\title{
Effects of Solidification Conditions on Grain Refinement Capacity of TiC in Directionally Solidified Ti6Al4V Alloy
}

\author{
NAOKI DATE, SHUNYA YAMAMOTO, YOSHIMI WATANABE, HISASHI SATO, \\ SHIZUKA NAKANO, NAOKO SATO, and SHINSUKE SUZUKI
}

\begin{abstract}
In this study, the effects of solidification conditions on the grain refinement capacity of heterogeneous nuclei $\mathrm{TiC}$ in directionally solidified Ti6Al4V alloy were investigated using experimental and numerical approaches. Ti6Al4V powder with and without $\mathrm{TiC}$ particles in a Ti6Al4V sheath was melted and directionally solidified at various solidification rates via the floating zone melting method. In addition, by using the phase field method, the microstructural evolution of directionally solidified Ti6Al4V was simulated by varying the temperature gradient $G$ and solidification rate $V$. As the solidification rate increased, the increment of the prior $\beta$ grain number by $\mathrm{TiC}$ addition also increased. There are two reasons for this: first, the amount of residual potent heterogeneous nuclei $\mathrm{TiC}$ is larger. Second, the amount of $\mathrm{TiC}$ particles that can nucleate becomes larger. This is because increasing the constitutional undercooling $\Delta T_{\mathrm{c}}$ leads to the activation of a smaller radius of heterogeneous nuclei and a higher nucleation probability from each radius. At a cooling rate $R$ higher than that in the floating zone melting experiment $(R$ $=3$ to $1000 \mathrm{~K} / \mathrm{s}$ ), the maximum degree of constitutional undercooling $\Delta T_{\mathrm{c}, \text { Max }}$ has a peak value, which suggests that constitutional undercooling $\Delta T_{\mathrm{c}}$ has a smaller contribution at higher cooling rates, such as those that occur during electron beam melting (EBM), including laser powder bed fusion (LPBF).
\end{abstract}

https://doi.org/10.1007/s11661-021-06333-2

(C) The Author(s) 2021

\section{INTRODUCTION}

THE titanium alloy Ti6Al4V is the most widely used alloy in the medical, ${ }^{[1]}$ aircraft, and advanced aerospace industries $^{[2]}$ because of its high specific strength and excellent corrosion resistance ${ }^{[3]}$ It is well known that metals and alloys such as Ti6Al4V usually solidify with coarse columnar grain structures under normal casting conditions. However, these columnar grains are generally regarded as unfavorable because their presence can impart solidification defects and anisotropic mechanical

NAOKI DATE and SHUNYA YAMAMOTO are with the Graduate School of Fundamental Science and Engineering, Waseda University, Tokyo, Japan, 169-8555. Contact e-mail: n.date.11882@ruri.waseda.jp YOSHIMI WATANABE and HISASHI SATO are with the Graduate School of Engineering, Nagoya Institute of Technology, Nagoya, 466-8555, Japan. SHIZUKA NAKANO is with the National Institute of Advanced Industrial Science and Technology, Tsukuba, 305-8564, Japan and also with the Henry Monitor Inc., Suwa, 392-0012, Japan. NAOKO SATO is with National Institute of Advanced Industrial Science and Technology. SHINSUKE SUZUKI is with the Graduate School of Fundamental Science and Engineering, Waseda University and also with the Kagami Memorial Research Institute of Materials Science and Technology, Waseda University, Tokyo, 169-0051, Japan.

Manuscript submitted January 18, 2021; May 10, accepted 2021.

Article published online June 6, 2021 properties. Thus, grain refinement for alloys, which leads to a fine-equiaxed microstructure with optimum mechanical performance, is very important. Recently, Ti6Al4V has often been used in additive manufacturing, and the formation of columnar grains has been commonly reported. ${ }^{[4]}$ Thus, a fine-equiaxed microstructure is desired in additive manufacturing.

The addition of heterogeneous nuclei is an effective way to form fine-equiaxed microstructures, and it is widely applied in practice, such as in casting. Previous studies on grain refiners have mainly focused on cast aluminum alloys, ${ }^{[5-7]}$ and a number of mature, commercially utilized grain refining solutions for aluminum alloys have been produced. ${ }^{[8-10]}$ Other systems, such as titanium alloys, have few known potent heterogeneous nuclei; however, various studies on Ti6Al4V grain refiners have been conducted in recent years, and some effective grain refiners for Ti6Al4V have been identified, such as $\mathrm{Nb}, \mathrm{W}$, and $\mathrm{La}_{2} \mathrm{O}_{3} \cdot{ }^{[1,12]} \mathrm{TiC}$ has also been found to be an effective grain refiner. For example, Watanabe et al. clarified that the addition of approximately 0.3 vol pct of $\mathrm{TiC}$ particles resulted in grain refinement of Ti6Al4V during laser powder bed fusion of metals. ${ }^{[13]}$ Yamamoto et al. clarified that fine-equiaxed prior $\beta$ grains were formed in the directionally 
solidified Ti6Al4V alloy by $\mathrm{TiC}$ addition, and the number of grains increased with increasing $\mathrm{TiC}$ addition. Moreover, TiC particles partially melted in molten Ti6Al4V, and fine-equiaxed grains were generated from the residual TiC particles. ${ }^{[14]}$ Although it is known that fine-equiaxed grains can be obtained at high solidification rates, in general, the effects of solidification rates on the amount of residual $\mathrm{TiC}$ particles present during the process and the grain refinement capacity of $\mathrm{TiC}$ particles in directionally solidified Ti6A14V alloy have not been clarified.

The multi-phase field method (MPFM) coupled with the database of calculation phase diagrams (CALPHAD) is a powerful tool for the simulation of solidification microstructural evolution, and many studies on equiaxed solidification by MPFM and CALPHAD have been reported. Bottger et al. reported that the combination of an MPFM and a nucleation model for multi-element systems is valuable for simulating the refinement process during the equiaxed solidification of an aluminum alloy. ${ }^{[15]}$ In this research, nucleation is simulated by statistically distributed seed particles, considering the shielding of nucleation sites by recalescence, solute diffusion, and growth of the solid phase. Nomoto et al. also simulated grain refinement during the equiaxed solidification of alloys belonging to the Al-Ti-B and Al-Si-Ti-B systems by MPFM together with CALPHAD. ${ }^{[16]}$ In particular, in the field of titanium alloy Ti6A14V, some studies on the microstructural evolution simulation of Ti6Al4V alloy in additive manufacturing using the phase field method have been reported; however, few studies have been reported on the effects of the solidification rate and temperature gradient on the grain refinement capacity of $\mathrm{TiC}$ in directionally solidified Ti6A14V. In addition, in general, changing the solidification rates leads to a difference in the constitutional undercooling $\Delta T_{\mathrm{c}}$ provided by the solute in the liquid ahead of the growing solid-liquid interface, and which affects heterogeneous nucleation. By using a MPFM coupled with CALPHAD, constitutional undercooling $\Delta T_{\mathrm{c}}$ provided by aluminum and vanadium solutes around the solidification front can be obtained, and the directional solidification process of Ti6Al4V can be visualized.

The objective of this study is to clarify the effects of solidification rate on the amount of residual $\mathrm{TiC}$ particles and the grain refinement capacity of $\mathrm{TiC}$ particles in directionally solidified Ti6Al4V alloy using experimental and numerical approaches. Ti6Al4V powders with and without $\mathrm{TiC}$ particles were melted and solidified directionally at various solidification rates via the floating zone melting method. In addition, by using the MPFM coupled with CALPHAD, the microstructural evolution of Ti6Al4V during directional solidification under varying temperature gradient and solidification rate was simulated. Thereafter, the effects of constitutional undercooling $\Delta T_{\mathrm{c}}$ on heterogeneous nucleation from $\mathrm{TiC}$ particles were investigated. The experimental conditions of temperature gradient and solidification rate as well as the higher cooling rate and lower temperature gradient were simulated, and the effects of the thermal conditions of the solidification process on the grain refinement capacity of $\mathrm{TiC}$ were investigated.

\section{EXPERIMENTAL AND SIMULATION PROCEDURE}

\section{A. Directional Solidification}

Figure 1 shows the sample rods that were prepared by filling a Ti6A14V sheath with the material powder. Ti6Al4V powder $(<\varphi 45 \mu \mathrm{m}$, Osaka Titanium Technologies Co., Ltd.) was used as the raw material, and the compositions of the Ti6Al4V sheath and powder are listed in Table I. TiC particles $(<\varphi 5 \mu \mathrm{m}$, Kojundo Chemical Laboratory Co., Ltd.) were mixed with Ti6Al4V powder in a cylindrical bottle $(\varphi 95 \mathrm{~mm}$ in diameter, $184 \mathrm{~mm}$ in length) that was rotated for 1 hour. The nominal TiC fractions were 0.0 and 2.0 vol pet for the mixed powder, as shown in Table II. The mass of the added TiC particles was calculated using the density of solid Ti6Al4V $\left(4.43 \times 10^{3} \mathrm{~kg} / \mathrm{m}^{3[17]}\right)$ and TiC $\left(4.93 \times 10^{3}\right.$ $\left.\mathrm{kg} / \mathrm{m}^{3[18]}\right)$.

The size distribution of the TiC particles was measured using a particle analyzer (qNano, IZON Science Ltd.), as shown in Figure 2. The maximum particle diameter $d_{\max }$ was $3.43 \mu \mathrm{m}$, the minimum particle diameter $d_{\min }$ was $0.947 \mu \mathrm{m}$, the mean particle diameter $d_{\text {mean }}$ was $1.41 \mu \mathrm{m}$, and the standard deviation of the particle distribution $\sigma$ was 0.323 . The qNano operates on the basis of scanning ion occlusion spectroscopy (SIOS) technology, which is similar to the coulter technique, also known as resistive pulse sensing. The tested $1 \mathrm{~g}$ of TiC sample had $18.8 \times 10^{12}$ particles, and in this study, the number of particles in the 2.0 vol pet $\mathrm{TiC}(0.340 \mathrm{~g})$ was estimated to be $6.41 \times 10^{12}\left(1.60 \times 10^{5} \mathrm{~mm}^{-3}\right)$.

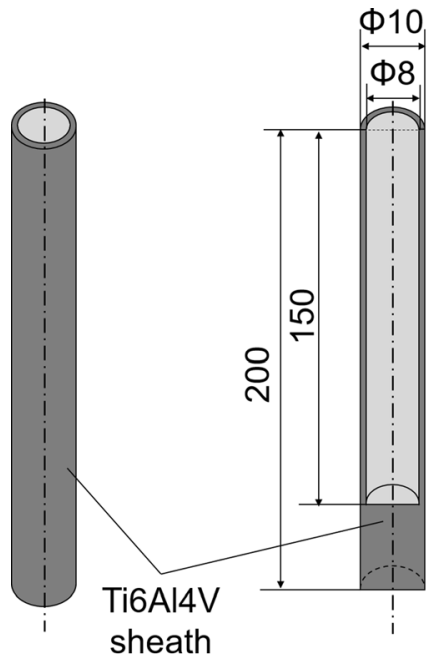

(a) (b)

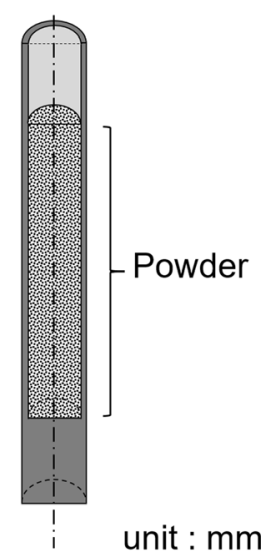

(c)
Fig. 1-Schematic illustration of a sample. (a) Ti6Al4V sheath, (b) cross section of Ti6Al4V sheath, and $(c)$ cross section of sample with powder. 
Table I. Composition of Ti6Al4V Powder and Sheath (Mass Pct)

\begin{tabular}{lccccccrrr}
\hline & Al & V & Fe & O & C & H & N & Ti \\
\hline Powder & 6.22 & 3.99 & 0.190 & 0.140 & 0.008 & 0.007 & 0.004 & Bal. \\
Sheath & 6.13 & 4.30 & 0.22 & 0.15 & 0.027 & 0.0017 & 0.003 & Bal. \\
\hline
\end{tabular}

Table II. TiC Addition Amount

\begin{tabular}{lcc}
\hline Sample Name & $\begin{array}{c}\text { Nominal Amount } \\
\text { (to Powder) } \\
\text { Vol Pct }\end{array}$ & $\begin{array}{c}\text { Substantial Amount } \\
\text { (to Sheath and Powder) } \\
\text { Vol Pct/Mass Pct }\end{array}$ \\
\hline Without TiC & 0.0 & $0.0 / 0.0$ \\
With TiC & 2.0 & $1.1 / 0.27$ \\
\hline
\end{tabular}

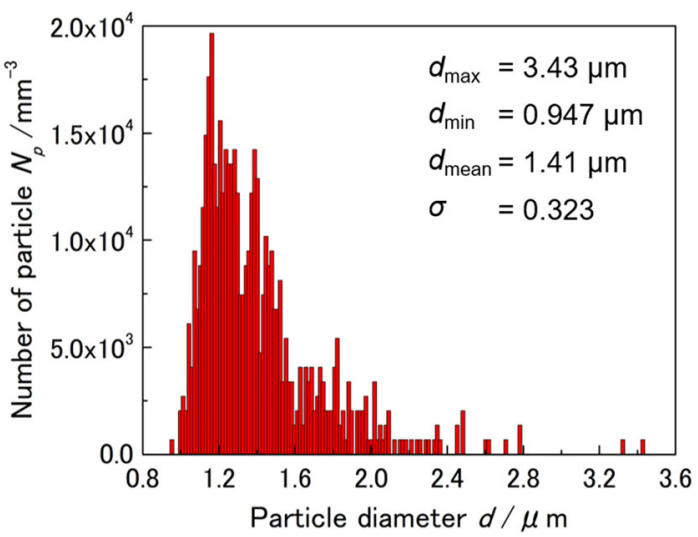

Fig. 2 - Size distribution of TiC particles. In the figure, $d_{\max }, d_{\min }$, $d_{\text {mean }}$, and $\sigma$ represent the maximum particle diameter, minimum particle diameter, mean particle diameter, and standard deviation of the size distribution, respectively.

The samples were melted and solidified directionally at various pulling rates $(=1,3,5,10$, and $15 \mathrm{~mm} / \mathrm{min})$ by the floating zone melting method. In this study, the pulling rate was described as the solidification rate $V$ because the vertical length of the melt pool was almost the same during directional solidification, and the pulling rate was considered to be equal to the solidification rate. The experimental flow is illustrated in Figure 3. The sample was placed in a quartz glass tube, and a high-frequency induction heating coil was set outside the glass tube. To prevent oxidation of the samples, the glass tube was evacuated and filled with Ar gas to less than $6 \mathrm{~Pa}$ before heating. This replacement was repeated three times. Then, the sample was heated at $2.3 \mathrm{~kW}$. After the sample was melted and solidified for longer than $90 \mathrm{~mm}$, heating and moving were stopped.

\section{B. Temperature Measurement}

During melting and solidification, the temperature around the melt pool was measured using a two-color pyrometer (Thermera-seenU, Mitsui Photonics. Ltd.), and a temperature gradient $G$ at position $z$ (defined as the interface between the melt pool and the solidified part, as shown in Figure 4) at various solidification rates ( $V=1,3,5,10$, and $15 \mathrm{~mm} / \mathrm{min}$ ) was obtained. This temperature gradient was derived from the temperature distribution between $z$ and $z+3 \mathrm{~mm}$ using the least-squares method.

\section{Microstructure Observation}

After directional solidification, the samples were cut into eight pieces (every $10 \mathrm{~mm}$ in the range between $z=$ 0 and $80 \mathrm{~mm}$, where the top side of the induction coil before the movement began was defined as the position $z$ $=0 \mathrm{~mm}$ ), and each piece was cut through the center in the longitudinal direction. After polishing with a series of emery papers (P600, P1200, and P2400) and buffing with diamond suspension $(6 \mu \mathrm{m}$ and $1 \mu \mathrm{m})$, the cross section was etched with Kroll's etchant and observed to evaluate the geometry of the grains.

The prior $\beta$ grains were observed through optical microscopy (OM, VHX-5000, Keyence Corporation), and when observing the grains, the region between each piece of approximately $1 \mathrm{~mm}$ was complemented. The aspect ratio ( $=L_{z}$ (height of the grain) $/ L_{x}$ (width of the grain)), equivalent diameter $d_{\mathrm{eq}}$, and the number of prior $\beta$ grains were evaluated, as shown in Figure 5.

\section{Concentration Analysis}

The composition of the TiC-added samples was analyzed using an electron probe microanalyzer (EPMA, JXA8100, JEOL Ltd.). The amounts of the elements- $\mathrm{Ti}, \mathrm{Al}, \mathrm{V}, \mathrm{C}$, and $\mathrm{O}$-were measured quantitatively at two points of $z=20 \mathrm{~mm}$, and EPMA mapping around the precipitates was obtained. The images of precipitates around positions $\mathrm{z}=20,40$, and $60 \mathrm{~mm}$ were observed using an optical microscope $(\mathrm{OM})$, and the area percentage of these precipitates was measured using image processing software (WinRoof, Mitani Corporation).

\section{E. Phase Field Simulation}

In this study, a phase field model was applied. Based on the experimental parameters of the floating zone (solidification rate $V$ and temperature gradient $G$ ), the effects of the solidification rate on the grain refinement capacity of $\mathrm{TiC}$ were assessed qualitatively based on more specific aspects, such as heterogeneous nuclei radius and the number of nucleated grains of the simulation results. Simulations were performed using phase field software MICRESS 7.01 and 


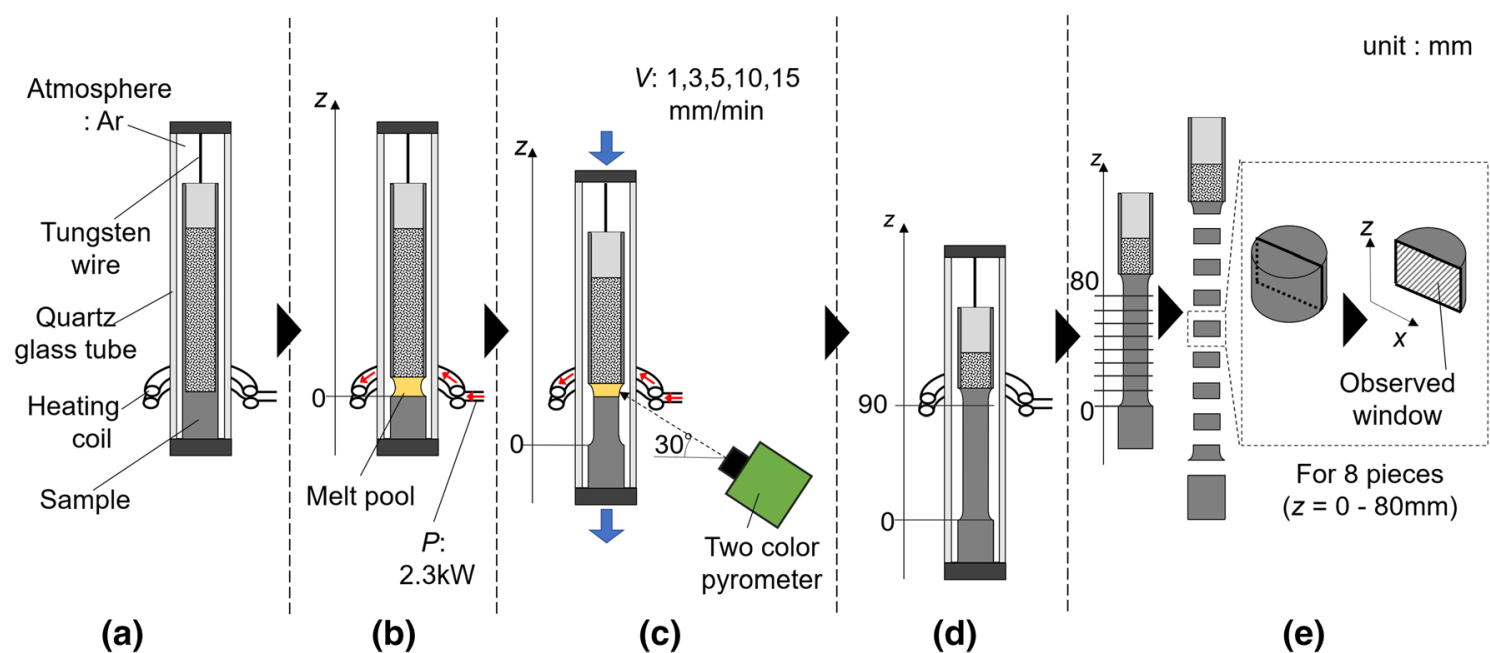

Fig. 3-Flow of the experiment. (a) Sample is placed in a floating zone melting apparatus, $(b)$ partial melting of sample and moving begins, $(c)$ sample moves downward and the temperature of the melt pool is monitored by a two-color pyrometer, $(d)$ heating and moving stop, and $(e)$ the sample is cut into eight pieces for observation.

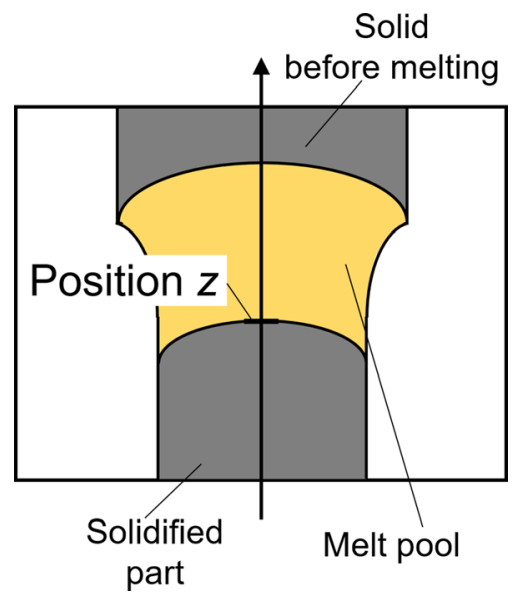

Fig. 4 - Schematic image obtained by two-color pyrometer. (position $z$ is defined as the interface between the melt pool and the solidified part).

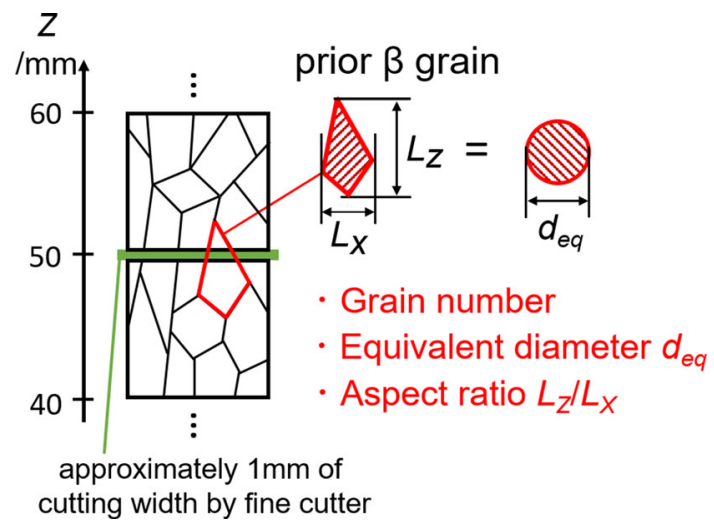

Fig. 5- Schematic images of the evaluation of prior $\beta$ grains. Grain number, equivalent diameter $d_{\mathrm{eq}}$, and aspect ratio $L_{z} / L_{x}$ of the prior $\beta$ grain were evaluated. thermodynamic data for the Ti-Al-V system were derived using Thermo-Calc software from the CALPHAD database. SSOL7 was used as the thermodynamic database for general alloys, including titanium, aluminum, and vanadium. In addition, MOBTi was used as the diffusion mobility database for the titanium alloys. Table III shows the material properties of the Ti6Al4V alloy used in this simulation.

In the present simulations, to consider solidification from liquid to $\beta(\mathrm{Ti})$, two liquid and $\beta(\mathrm{Ti})$ phases were modeled, and the solid-phase transformation from $\beta(\mathrm{Ti})$ to $\alpha(\mathrm{Ti})$ was not considered. To model the heterogeneous nucleation of $\beta(\mathrm{Ti})$ grains from $\mathrm{TiC}$, the seed density model implemented in MICRESS was used. This model describes how nucleation from the melt is triggered by small seeding particles. In principle, the critical nucleation undercooling $\Delta T_{\mathrm{n}}$ of a given phase on the seeding particles depends essentially on the radius of the seeding particle and the surface energy of the new phase in the liquid. If a radius-density distribution of the seeding particles is specified, depending on the cooling conditions, the model can predict the number of nuclei formed. Thus, it is necessary to input the distribution density versus the size of the $\mathrm{TiC}$ particles as potential sites for the nucleation of $\beta(\mathrm{Ti})$. TiC potential sites for $\beta(\mathrm{Ti})$ nucleation were randomly placed in the simulation domain. The value for critical nucleation undercooling $\Delta T_{\mathrm{n}}$ was calculated from the particle size according to the hemispherical cap model. ${ }^{[21]}$ In this study, the size distribution of $\mathrm{TiC}$ particles obtained by a particle analyzer (qNano, IZON Science Ltd.), as shown in Figure 2, was used, and the total seed density number was set to $1 \times 10^{10} \mathrm{~m}^{-3}$ for all simulation cases. Figure 6 shows the seed density distribution used in this simulation.

$$
R[\mathrm{~K} / \mathrm{s}]=\frac{G[\mathrm{~K} / \mathrm{mm}] \times V[\mathrm{~mm} / \mathrm{min}]}{60} .
$$


Table III. Material Properties of Ti6Al4V

\begin{tabular}{lll}
\hline Interface Energy Between & $0.8^{[19]}$ \\
Liquid and $\beta(\mathrm{Ti})\left[\mathrm{J} \cdot \mathrm{m}^{-2}\right]$ & \\
Interface Mobility Between & $4 \times 10^{-2}$ \\
Liquid and $\beta(\mathrm{Ti})\left[\mathrm{m}^{4} \cdot \mathrm{J}^{-1} \cdot \mathrm{s}^{-1}\right]$ & \\
Liquid Diffusion Coefficient $\left[\mathrm{m}^{2} \cdot \mathrm{s}^{-1}\right]$ & $\mathrm{Al}$ & $9.5 \times 10^{-9[20]}$ \\
& $\mathrm{V}$ & $9.5 \times 10^{-9[20]}$ \\
\hline
\end{tabular}

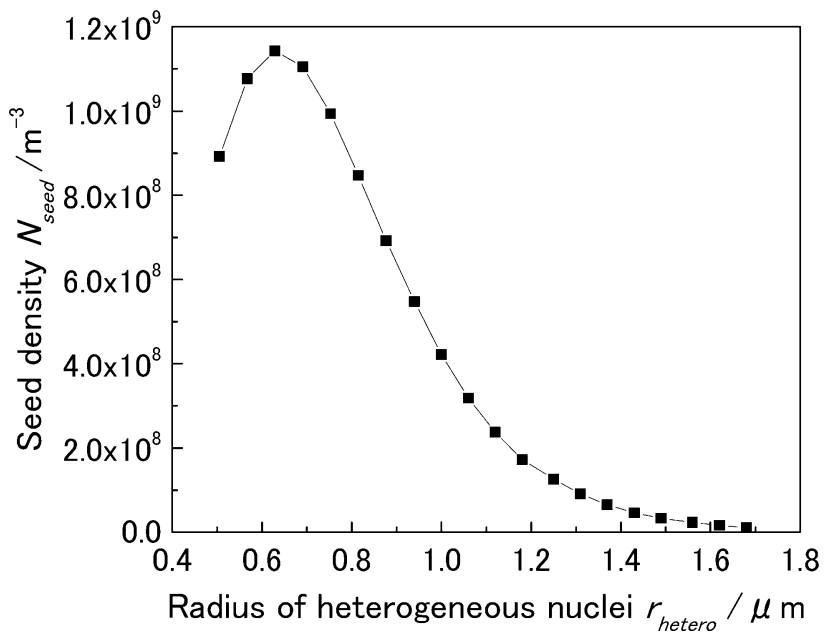

Fig. 6-Seed density distribution used in this simulation.

The thermal condition of the simulation is determined using Eq. [1]. The value of the temperature gradient $G$ was obtained from the temperature distribution in the melt pool discussed in part IV.A. In particular, at $V=1$ and $3 \mathrm{~mm} / \mathrm{min}$, the temperature gradient $G$ was obtained by linear interpolation of other values of temperature gradient $G$. Table IV shows the thermal conditions of the floating zone experiment used in this simulation.

Figure 7 shows the simulation domain of $2000 \times 2 \times 4000 \mu \mathrm{m}(1000$ cells $\times 1$ cell $\times 2000$ cells, cell size of $2 \mu \mathrm{m})$. A thin layer of solid $\beta(\mathrm{Ti})$ phase $(2000$ $\mu \mathrm{m} \times 2 \mu \mathrm{m} \times 8 \mu \mathrm{m})$ was placed at the bottom of the domain. Solid grains starting from the bottom phase grow epitaxially as observed in the floating zone method. In this domain, the number of heterogeneous nuclei was 84 , and this was automatically calculated from the total seed density $\left(1 \times 10^{10} \mathrm{~m}^{-3}\right)$ and size of the simulation domain.

The validity of simulation outputs was confirmed by comparison with the experimental results. As discussed in Section III, the experimental results show that the amount of grains increased as $\mathrm{TiC}$ addition increased and as the solidification rate increased. In addition, in the phase field simulation using the experimental temperature gradient $G$ and solidification rate $V$, the number of nucleated grains was larger and more fine-equiaxed grains appeared as the solidification rate increased. As discussed above, the simulation outputs qualitatively agreed well with the experimental results.

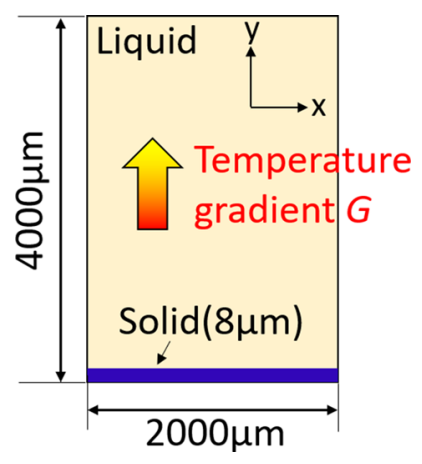

Fig. 7-Simulation domain of $2000 \mu \mathrm{m} \times 2 \mu \mathrm{m} \times 4000 \mu \mathrm{m}$. The temperature gradient is imposed along the $y$-axis as indicated. A thin layer of solid $\beta(\mathrm{Ti})$ phase $(2000 \mu \mathrm{m} \times 2 \mu \mathrm{m} \times 8 \mu \mathrm{m})$ was set at the bottom of the domain.

\section{RESULTS}

\section{A. Temperature in a Melt Pool}

When measuring the temperature of the melt pool using a two-color pyrometer, a vapor deposition layer was observed on the inner surface of the glass tube at all solidification rates. Figure 8 shows the images of the melt pool that were measured by the two-color pyrometer at each solidification rate. In the images, vapor deposition was observed as the shadow, and the vapor deposition layer on the glass tube made the images slightly dark. As the solidification rate decreases, the shadow becomes darker because a thicker vapor deposition layer is formed, and this vapor deposition disrupts the measured temperature distribution in the melt pool. Figure 9 shows the temperature distribution of the melt pool as measured using two-color pyrometer images. At any solidification rate, the temperature distributions tend to increase as the position $z$ increases. The temperature of the melt pool was lower than the liquidus Ti6A14V temperature $\left(1943 \mathrm{~K}^{[22]}\right)$, and the temperature gap between the measured and liquidus temperatures increased as the solidification rate decreased. More details are discussed in part IV.A. The two-color pyrometer operates by determining the ratio of the brightness temperatures at two wavelengths of the image. Thus, slightly dark vapor deposition layer images can result in errors in measuring the temperature of the melt pool, and thus, this vapor deposition layer can lower the measured temperature. As the solidification rate decreases, the time to complete melting and solidification becomes longer, and the inner surface of the glass tube is exposed to the melt pool for a longer time. Thus, vapor deposition was more likely to occur, and the measured temperature decreased as the solidification rate decreased.

\section{B. Directionally Solidified Microstructure}

Figure 10 shows the directionally solidified Ti6Al4V microstructure with and without $\mathrm{TiC}$ particles observed between $z=30$ and $40 \mathrm{~mm}$. The micrographs shown in the row labeled with "After drawing G.B." are the edited images created by drawing black lines on the 
Table IV. Thermal Conditions of Floating Zone Experiment

\begin{tabular}{lccc}
\hline Label & $\begin{array}{c}\text { Solidification Rate } \\
V / \mathrm{mm} \cdot \mathrm{min}^{-1}\end{array}$ & $\begin{array}{c}\text { Temperature Gradient } \\
G / \mathrm{K} \cdot \mathrm{mm}^{-1}\end{array}$ & $\begin{array}{c}\text { Cooling Rate } \\
R / \mathrm{K} \cdot \mathrm{s}^{-1}\end{array}$ \\
\hline Conditions of FZ Experiment & 1 & 0.826 & 0.0138 \\
& 3 & 2.48 & 0.124 \\
& 5 & 8.64 & 0.387 \\
1.36 & 3.08 \\
\hline
\end{tabular}

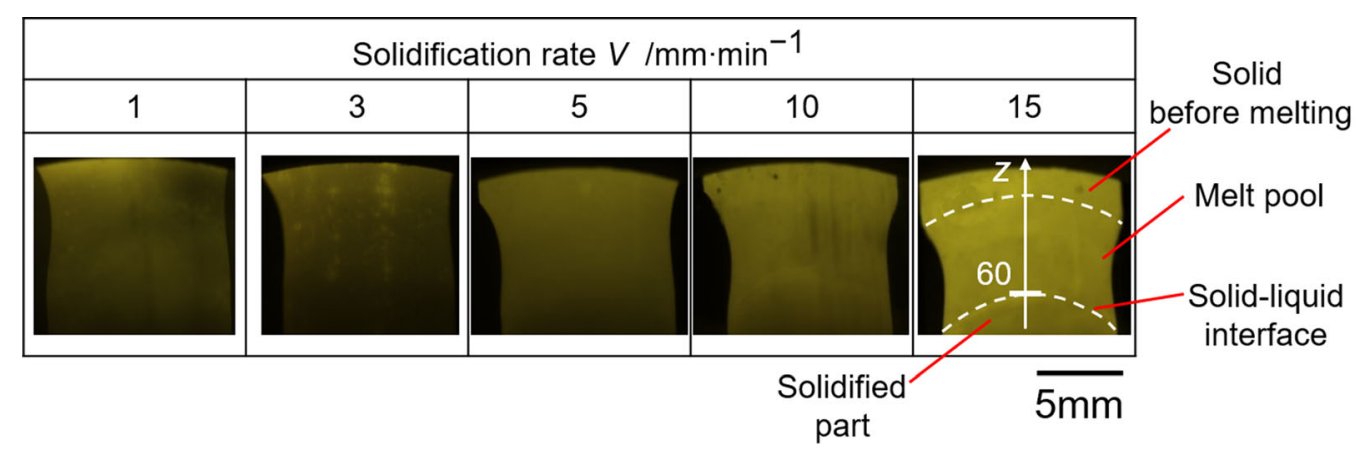

Fig. 8-Melt pool as observed by a two-color pyrometer at each solidification rate around $z=60 \mathrm{~mm}$. The upper side of the image shows the unsolidified part, and the lower side of the image shows the solidified part, and the middle section shows the melt pool.

prior $\beta$ grain boundaries (GB) that were judged by $\mathrm{OM}$ observation. The microstructure is composed of relatively large vertically elongated grains and isotropic small grains in a mixture, and this tendency was present over the entire microstructure.

Figure 11 shows the relationship between the solidification rate $V$ and the number of prior $\beta$ grains in the range from $z=0$ to $80 \mathrm{~mm}$. At all solidification rates, the total number of grains increased with the addition of TiC. In addition, the increase in grain number with the addition of $\mathrm{TiC}$ increased as the solidification rate increased. Especially at a solidification rate of $V=1$ $\mathrm{mm} / \mathrm{min}$ without TiC addition, the prior $\beta \mathrm{GB}$ did not appear over the entire microstructure. At a solidification rate of $V=1 \mathrm{~mm} / \mathrm{min}$ with $\mathrm{TiC}$ addition, large and small grains appeared in the mixture up to $z=40 \mathrm{~mm}$; however, the prior $\beta \mathrm{GB}$ did not appear above $z=40$ $\mathrm{mm}$, and there were no significant differences above $z=$ $40 \mathrm{~mm}$ with and without TiC. From these results, we can conclude that $\mathrm{TiC}$ addition has no effect on grain refinement at $V=1 \mathrm{~mm} / \mathrm{min}$, and $\mathrm{TiC}$ particles are effective for grain refinement of Ti6Al4V when the solidification rate $V$ is higher than $1 \mathrm{~mm} / \mathrm{min}$.

Figure 12 shows the cumulative number of prior $\beta$ grains relative to the equivalent diameter $d_{\text {eq. }}$. The number of relatively small grains increased with an increase in the solidification rate or $\mathrm{TiC}$ addition. Figure 13 shows the aspect ratio of the prior $\beta$ grains versus their equivalent diameter $d_{\text {eq }}$. With the addition of $\mathrm{TiC}$, grains with a relatively small $d_{\mathrm{eq}}$ and small aspect ratio appeared. As mentioned above, at a solidification rate of $V=1 \mathrm{~mm} / \mathrm{min}$, several GBs were observed in the sample with TiC, while no GB was observed in the sample without TiC. At a solidification rate of $V=1 \mathrm{~mm} / \mathrm{min}$ with $\mathrm{TiC}$, all of the $\mathrm{GB}$ were observed below $z=40 \mathrm{~mm}$, and no GBs was observed above $z=40 \mathrm{~mm}$.

\section{Composition and Fraction of Precipitates}

From the SEM observations shown in Figure 14, acicular-shaped precipitates, which were also observed in previous research, ${ }^{14]}$ appeared to cross the $\alpha+\beta$ phase in the TiC-added samples at all solidification rates ( $V=1,3,5,10$, and $15 \mathrm{~mm} / \mathrm{min})$. On the other hand, without the addition of $\mathrm{TiC}$, precipitates could not be observed regardless of solidification rates. Figure 15 shows EPMA mapping around the precipitates at a solidification rate of $V=1 \mathrm{~mm} / \mathrm{min}$. Focusing on the region of the precipitates, $\mathrm{Ti}, \mathrm{O}$, and $\mathrm{C}$ were mainly detected, and $\mathrm{C}$ was detected at a relatively higher level than any other element. A similar tendency was confirmed not only at $V=1 \mathrm{~mm} / \mathrm{min}$, but also at other solidification rates.

Table V shows the compositions of the precipitates at various solidification rates that were obtained by EPMA quantitative analysis. Regardless of the solidification rate, the fraction of $\mathrm{C}$ was approximately 10 mass pct (25-28 mol pct), and the fraction of Ti was 82 to 85 mass pct (52 to $54 \mathrm{~mol} \mathrm{pct}$ ) in the precipitates.

Figure 16 shows the images of the precipitates observed by $\mathrm{OM}$ at various solidification rates $(V=1$, $3,5,10$, and $15 \mathrm{~mm} / \mathrm{min}$ ) around $z=60 \mathrm{~mm}$ with TiC-added samples. From the images at $z=20,40$, and $60 \mathrm{~mm}$, the average area percentages of the precipitates were calculated. Figure 17 shows the relationship between the fraction of precipitates (area percentages) and solidification rates. There are some variations 


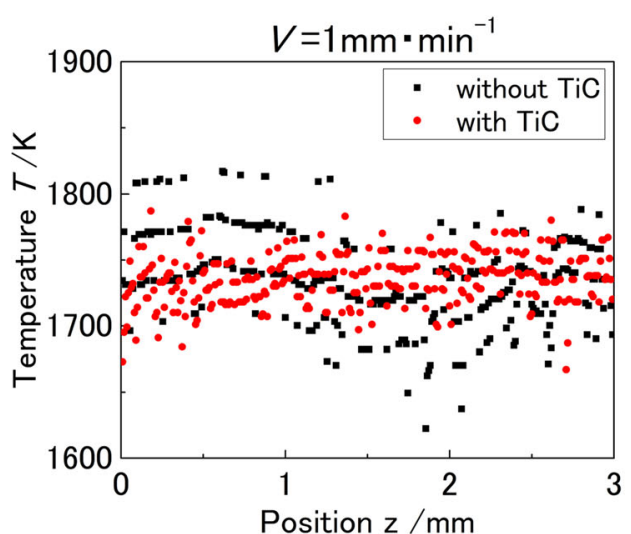

(a)

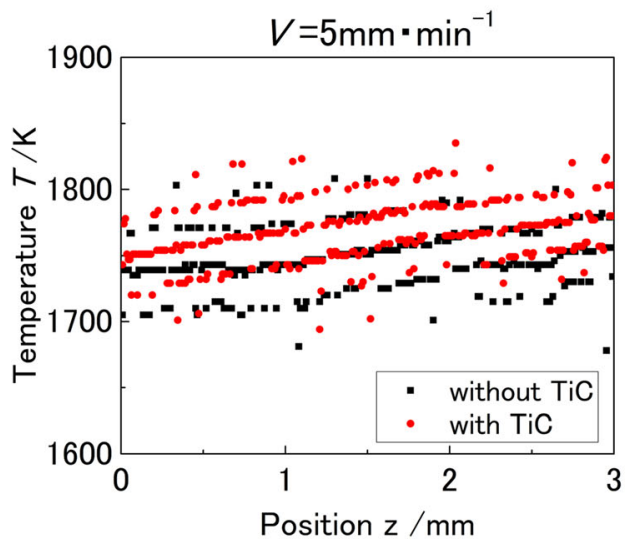

(c)

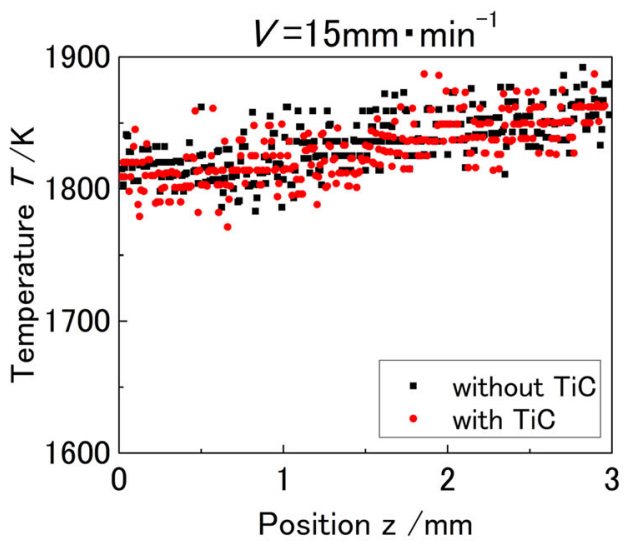

(e)

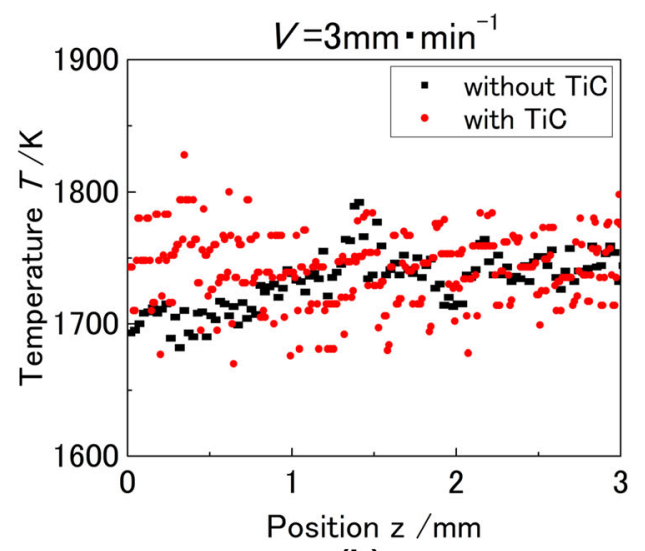

(b)

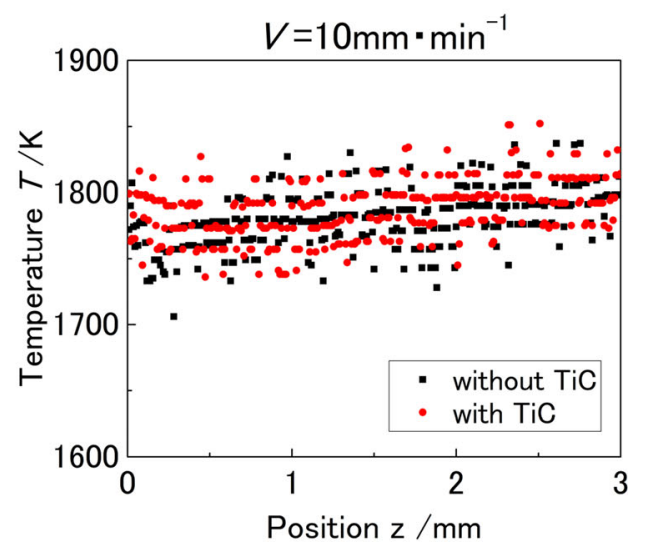

(d)

Fig. 9-Temperature distribution of the melt pool measured by two-color pyrometer images at $z=60 \mathrm{~mm}$. $(a) V=1 \mathrm{~mm} / \mathrm{min},(b) V=3 \mathrm{~mm} /$ min, (c) $V=5 \mathrm{~mm} / \mathrm{min},(d) V=10 \mathrm{~mm} / \mathrm{min}$, and (e) $V=15 \mathrm{~mm} / \mathrm{min}$.

between the $\mathrm{z}$-direction $(z=20,40$, and $60 \mathrm{~mm})$ in the figures; however, in terms of solidification rates, there is a tendency that the area percentage of the precipitates decreases with increasing solidification rates.

\section{Simulated Microstructure for Each $G$ and $V$ Condition of the Floating Zone Experiment}

Figure 18 shows the simulated microstructure for each $G$ and $V$ condition of the floating zone experiment.
In the first stage of solidification, a thin layer of solid $\beta$ (Ti) phase at the bottom of the domain grew epitaxially in the direction of the temperature gradient. Subsequently, nucleation from heterogeneous nuclei occurred. The number of grains was 4 at $V=1 \mathrm{~mm} / \mathrm{min}, 15$ at $V$ $=3 \mathrm{~mm} / \mathrm{min}, 27$ at $V=5 \mathrm{~mm} / \mathrm{min}, 52$ at $V=10 \mathrm{~mm} /$ min, and 70 at $V=15 \mathrm{~mm} / \mathrm{min}$. As the solidification rate increased, the number of nucleated grains increased, and more fine-equiaxed grains appeared. Figure 19 shows the predicted segregation of aluminum and 


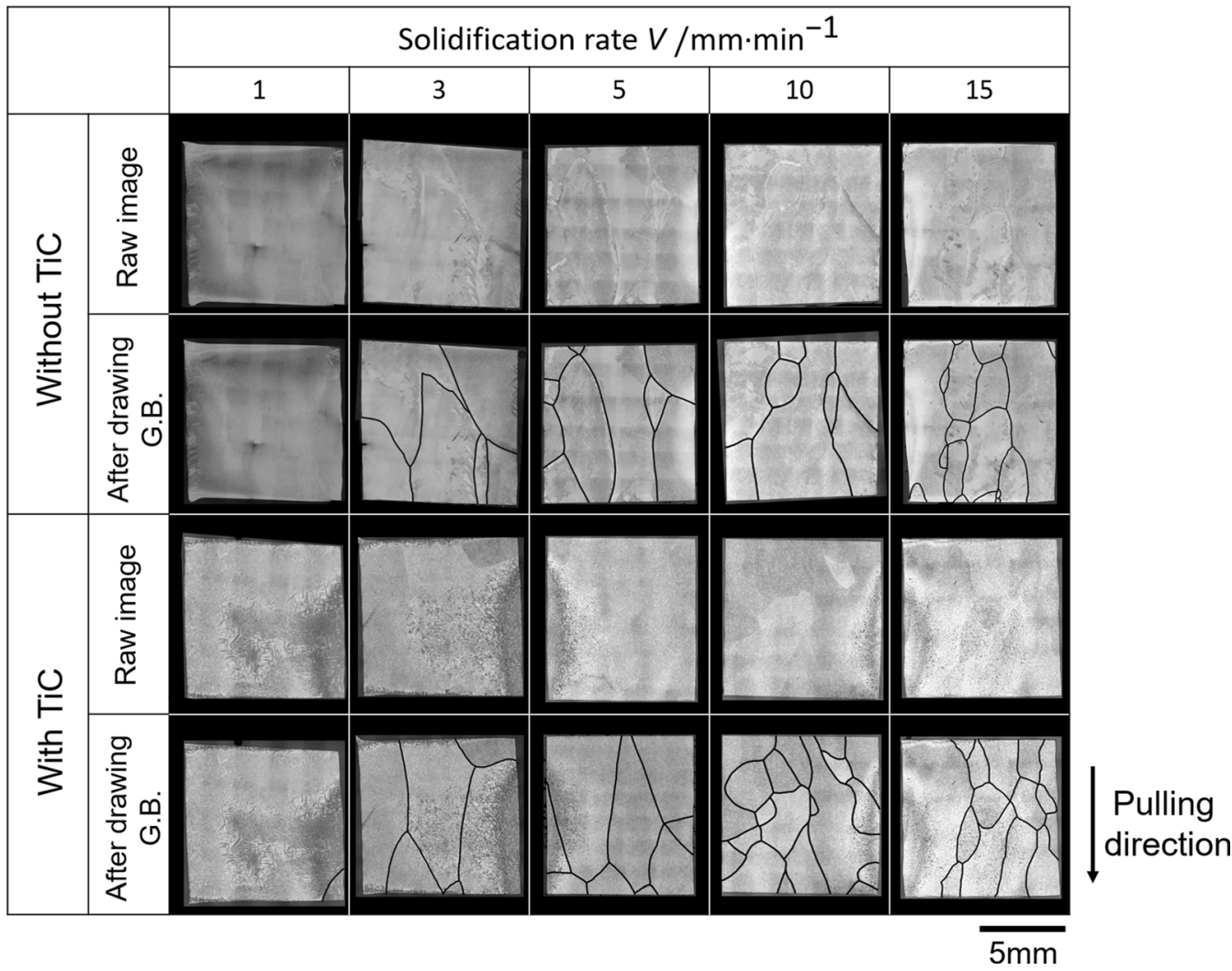

Fig. 10-Directionally Solidified Ti6Al4V Microstructure With and Without TiC (between $z=30$ and $40 \mathrm{~mm}$ ). The micrographs shown in the row with "After drawing G.B." are the edited images created by drawing black lines on the prior $\beta$ grain boundaries (GB) judged by OM observation.

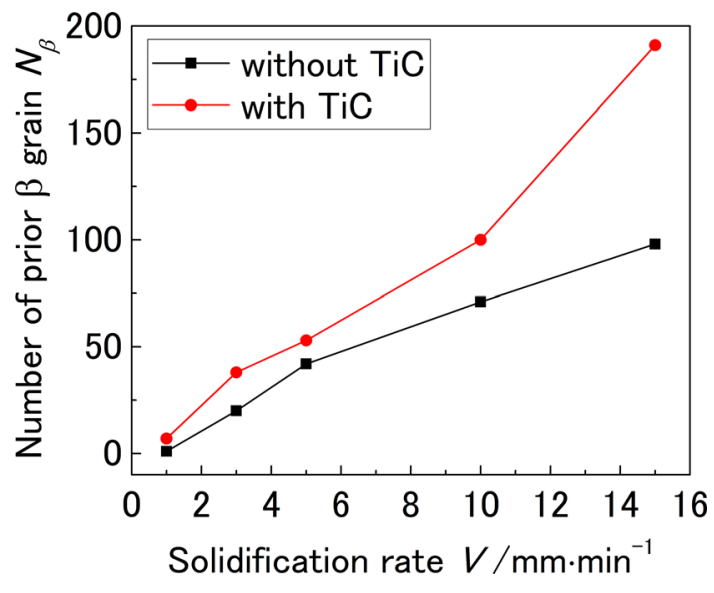

Fig. 11-Relationship between solidification rate $V$ and the number of prior $\beta$ grains counted in the range from $z=0$ to $80 \mathrm{~mm}$.

vanadium during solidification, and Figure 20 shows the solute profiles of aluminum and vanadium extracted at a steady state for each $G$ and $V$ condition. The extracted line of the solute profile was set to the nucleation front of the grains; at the time, the grain radius reached 100 $\mu \mathrm{m}$. As shown in Figure 19, the vanadium solute was rejected from the interface of an already nucleated and growing grain, whereas the aluminum solute was thickened at the solid side of the interface. Although these profiles could vary a little depending on location and were also affected by the surrounding grains, they presented a typical scenario for each case. As shown in Figure 20, as the solidification rate increased, the vanadium solute accumulated, and the aluminum solute was more thickened at the solid side of the interface. Furthermore, the solute diffusion length decreased as the solidification rate increased.

\section{DISCUSSION}

\section{A. Temperature Gradient $G$ in the Melt Pool}

During melting and solidification, the temperature around the melt pool was measured using a two-color pyrometer, and the temperature gradient $G$ at position $z$ (interface between the melt pool and the solidified part) at various solidification rates $(V=1,3,5,10$, and 15 $\mathrm{mm} / \mathrm{min}$ ) was obtained. Figure 21 shows the temperature gradient $G$ at various solidification rates $(V=1,3$, 5,10 , and $15 \mathrm{~mm} / \mathrm{min}$ ) at $z=0$ and $80 \mathrm{~mm}$. At any solidification rate, the temperature gradient $G$ varied significantly between $\mathrm{z}=0$ and $40 \mathrm{~mm}$. On the other hand, the temperature gradient $G$ was relatively steady between $z=40$ and $80 \mathrm{~mm}$. This is because the vapor deposition layer on the glass tube around $z=0 \mathrm{~mm}$ was thicker and unstable because the glass tube around $z=$ $0 \mathrm{~mm}$ existed near the melt pool longer than in the other parts. To avoid the effect of unstable vapor deposition, 


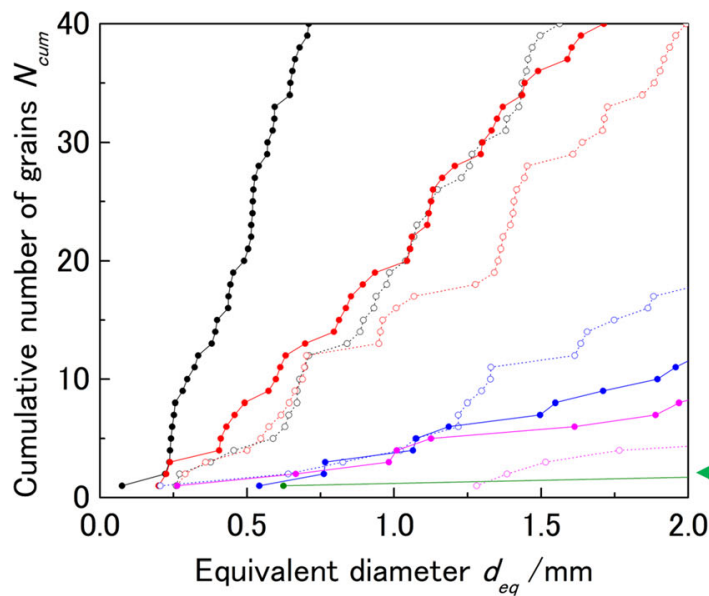

(a)

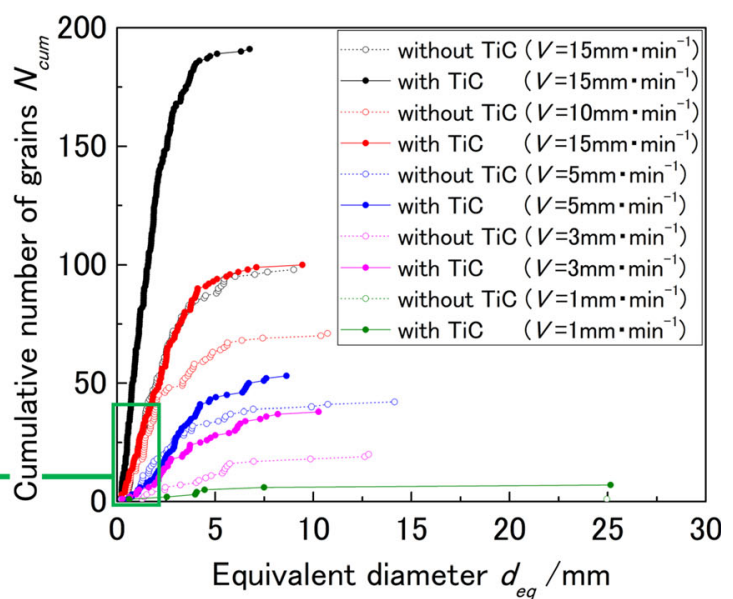

(b)

Fig. 12-Cumulative number of grains versus equivalent diameter $d_{\mathrm{eq}}$ for $(a)$ each solidification rate with and without TiC in the small region of equivalent diameter $d_{\mathrm{eq}}(0 \sim 2.0 \mathrm{~mm})$ and $(b)$ in the entire region of equivalent diameter $d_{\mathrm{eq}}(0 \sim 30 \mathrm{~mm})$.

the average temperature gradient was calculated using the value of $G$ between $z=40$ and $80 \mathrm{~mm}$. The average temperature gradient $G(z=40$ to $80 \mathrm{~mm})$ became relatively lower as the solidification rates decreased, and the average temperature gradient was approximately 5 $\mathrm{K} / \mathrm{mm}$ when $V=5 \mathrm{~mm} / \mathrm{min}, 8 \mathrm{~K} / \mathrm{mm}$ when $V=10$ $\mathrm{mm} / \mathrm{min}$, and $12 \mathrm{~K} / \mathrm{mm}$ when $V=15 \mathrm{~mm} / \mathrm{min}$. Because the samples both without and with $\mathrm{TiC}$ were heated at the same power of $2.3 \mathrm{~kW}$ at any solidification rate, the average temperature gradient was assumed to be the same. At solidification rates of $V=5,10$, and $15 \mathrm{~mm} /$ min, the temperature gradient was almost the same for both without and with $\mathrm{TiC}$. However, at solidification rates of $V=1$ and $3 \mathrm{~mm} / \mathrm{min}$, the difference in the average temperature gradient $(z=40$ to $80 \mathrm{~mm})$ between samples without and with $\mathrm{TiC}$ was relatively large. During solidification, a vapor deposition layer was formed uniformly in most cases; however, an uneven vapor deposition layer was formed when the solidification rate $V=3 \mathrm{~mm} / \mathrm{min}$ with the addition of TiC and $V=1 \mathrm{~mm} / \mathrm{min}$ without TiC. Furthermore, it was also observed that as the solidification rate decreased, the degree of the temperature gradient variation became larger between the positions of $z=$ 0 and $80 \mathrm{~mm}$ because a thicker vapor deposition layer was formed as the solidification rate decreased. It was confirmed that the temperature gradient was not linear at position $z$ and had a disarrayed value around the uneven deposition layer. Consequently, it is clear that the vapor deposition layer is an error factor affecting the temperature measurements of the melt pool and the temperature gradient. A two-color pyrometer measures the temperature by comparing the brightness of the images at two wavelengths and determines the temperature by taking the ratio of the two. If vapor deposition is formed during the temperature measurement, the brightness of the images decreases and the ratio of the two wavelengths changes and becomes different from its true value. Therefore, this indicates that the vapor deposition layer results in errors in measuring the temperature of the melt pool, and therefore, the vapor deposition layer lowers the measured temperature and disrupts the temperature gradient. However, in the entire microstructure $(z=0$ to $80 \mathrm{~mm})$, the prior $\beta$ grains were uniformly distributed along the longitudinal direction, although the temperature gradient between $z$ $=0$ and $40 \mathrm{~mm}$ varied significantly. Thus, it is considered that the temperature distribution variation (due to the vapor deposition layer) had little influence in this study.

\section{B. Precipitates $\mathrm{Ti}_{2} \mathrm{C}$ and Carbon Amount Derived from Melted $\mathrm{TiC}$}

From the EPMA mapping in Figure 15, oxygen was detected over the whole sample; however, the samples were not considered to be contaminated by oxygen during the process because of the existence of oxygen in both the matrix and the precipitates uniformly. Table VI shows the molar fraction of the precipitates, except for oxygen calculated from Table V. Almost all the precipitates consisted of $\mathrm{Ti}$ and $\mathrm{C}$, and these elements existed in a ratio of approximately 2:1 regardless of solidification rates, and Ti-rich titanium carbide appeared as well as the precipitates identified in previous research. ${ }^{[14]}$ Here, Ti-rich titanium carbide was defined as $\mathrm{Ti}_{2} \mathrm{C}$ precipitates. The presence of $\mathrm{Ti}_{2} \mathrm{C}$ precipitates suggests that $\mathrm{TiC}$ particles were partially melted into molten Ti6Al4V and melted carbon from TiC and matrix $\mathrm{Ti}$ precipitated as $\mathrm{Ti}_{2} \mathrm{C}$ regardless of the solidification rate. Figure 22(a) shows the phase diagram of the binary $\mathrm{TiC}$ system calculated by Thermo-Calc; if the carbon of the TiC particles diffuses into the molten Ti6Al4V, the melting point of $\mathrm{TiC}$ becomes lower, and thus, partial melting of $\mathrm{TiC}$ is reasonable. The residual $\mathrm{TiC}$ particles acted as heterogeneous nuclei in molten Ti6Al4V. Figures 22(b) and (c) show the phase diagrams of the pseudo-binary Ti6A14V-C system, which were calculated using the Ti-alloy thermodynamic databases of SSOL 7 and TTTI3, respectively. The phase diagram of the pseudo-binary Ti6A14V-C system using SSOL7 could not explain the validity of the precipitates. On 


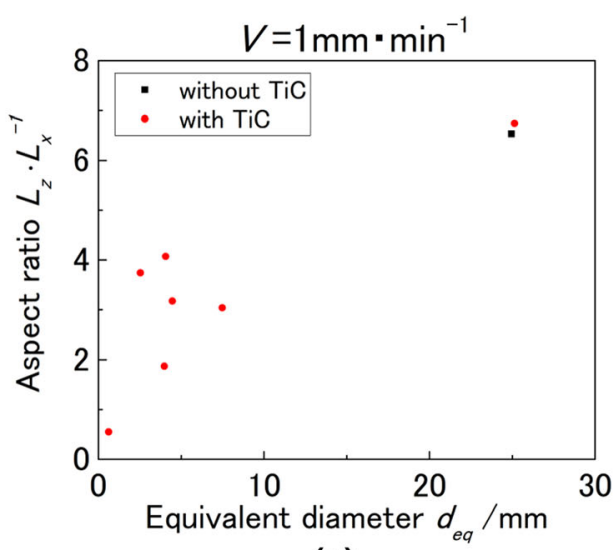

(a)

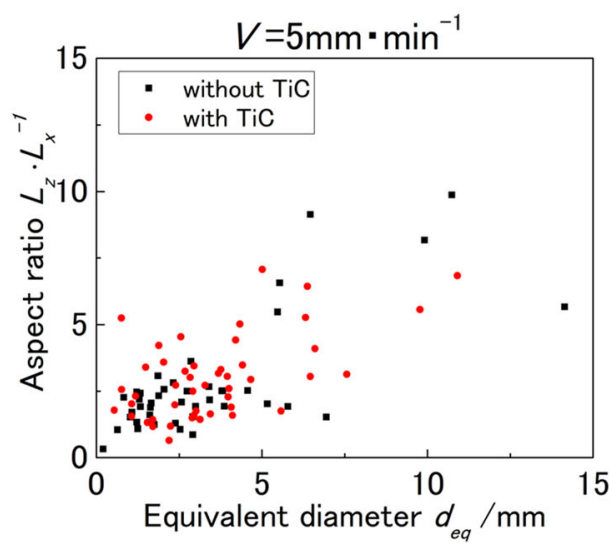

(c)

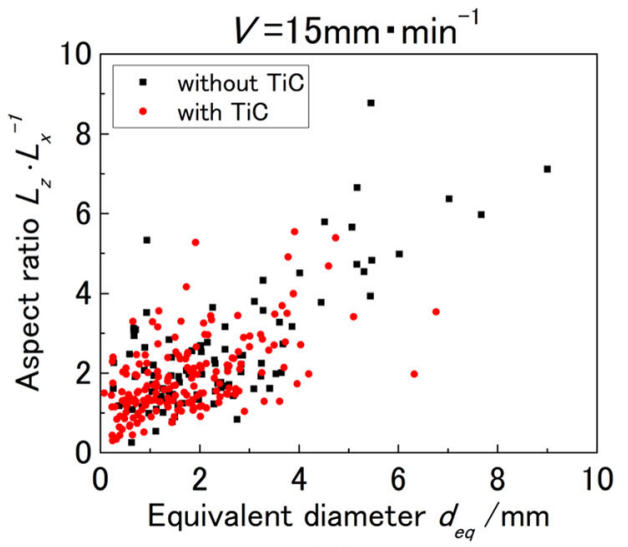

(e)

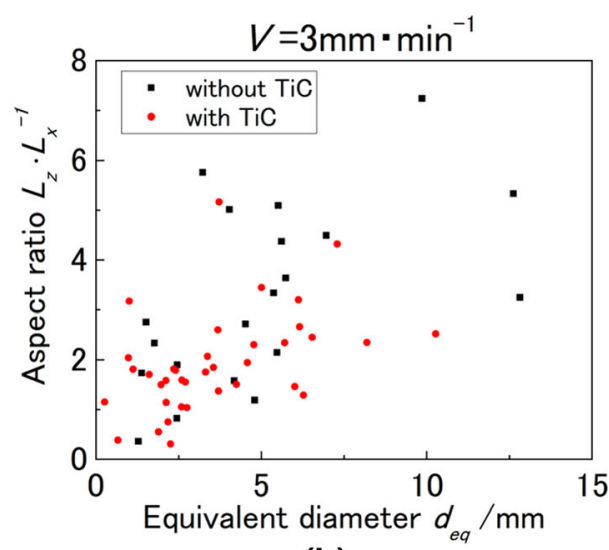

(b)

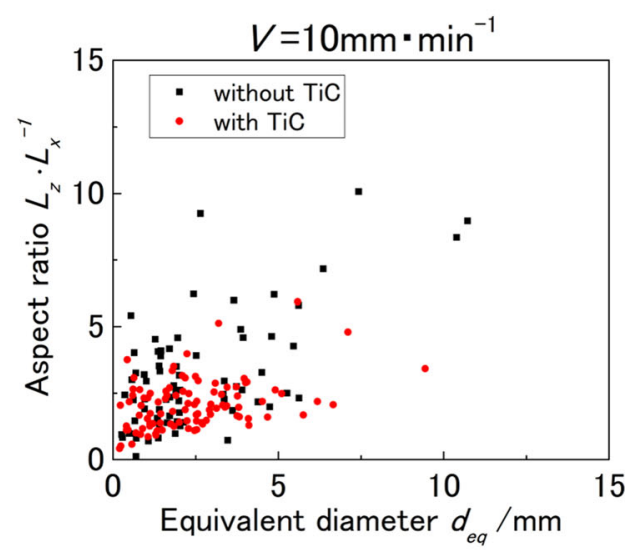

(d)

Fig. 13-Aspect ratio versus equivalent diameter of the prior $\beta$ grains. (a) $V=1 \mathrm{~mm} / \mathrm{min},(b) V=3 \mathrm{~mm} / \mathrm{min},(c) V=5 \mathrm{~mm} / \mathrm{min},(d) V=10$ $\mathrm{mm} / \mathrm{min}$, and $(e) V=15 \mathrm{~mm} / \mathrm{min}$.

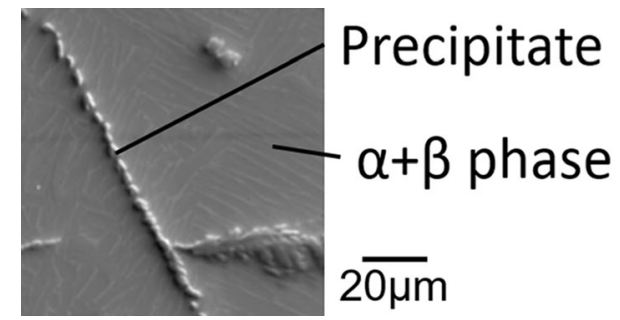

Fig. 14 -SEM image of precipitates observed in TiC-added samples at a solidification rate of $V=1 \mathrm{~mm} / \mathrm{min}$. the other hand, the phase diagram calculated using TTTI 3 could explain the validity of the precipitates, and Ti-rich titanium carbide formation is predicted with a carbon amount of 0.270 mass pet from 2.0 vol pet added $\mathrm{TiC}$ particles. Indeed, Ti-rich $\mathrm{Ti}_{2} \mathrm{C}$ appeared, as mentioned above.

Figure 23 shows the effects of the solidification rate on the amount of carbon derived from melted TiC. The melted carbon amount was calculated from the area percentages of $\mathrm{Ti}_{2} \mathrm{C}$, and the melting time was defined as the time at which the solidification interface passed 


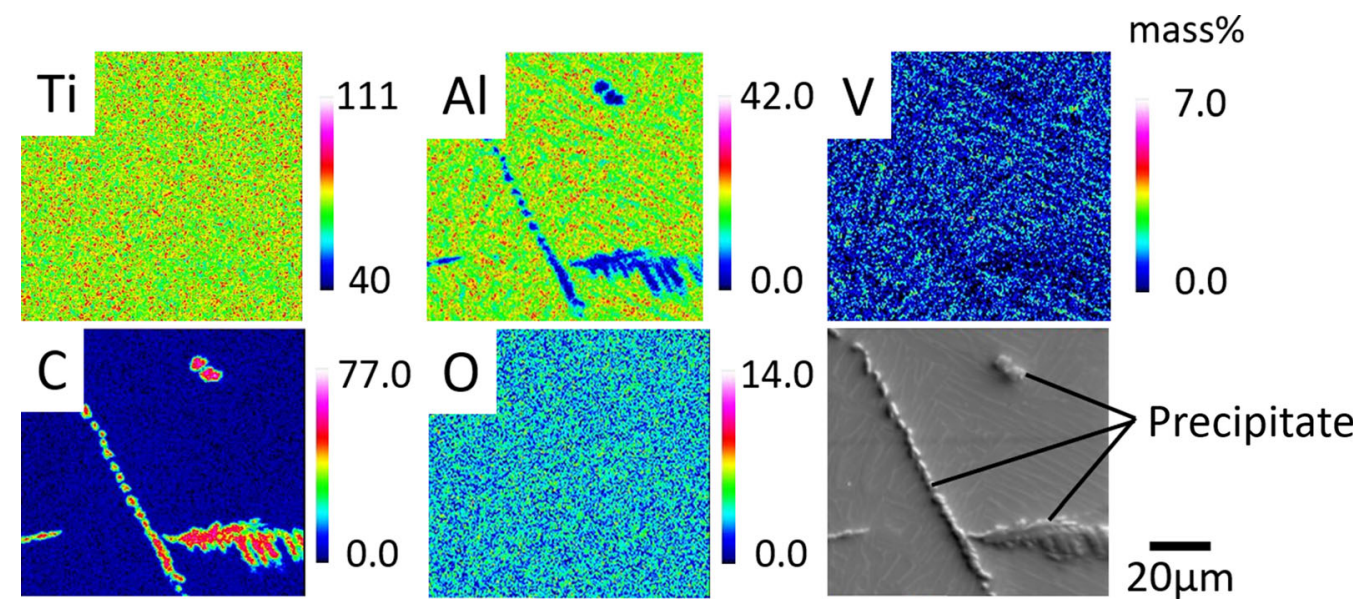

Fig. 15-EPMA mapping and SEM images around the precipitates in TiC-added samples at a solidification rate of $V=1 \mathrm{~mm} / \mathrm{min}$.

Table V. Mass Fraction of Elements in Precipitates Obtained by EPMA Quantitative Analysis (mass\% (mol\%))

\begin{tabular}{|c|c|c|c|c|c|}
\hline Solidification Rate $V / \mathrm{mm} \cdot \min ^{-1}$ & $\mathrm{Ti}$ & $\mathrm{Al}$ & $\mathrm{V}$ & $\mathrm{C}$ & $\mathrm{O}$ \\
\hline 1 & $\begin{array}{c}85.6 \\
(54.3)\end{array}$ & $\begin{array}{c}1.89 \\
(2.12)\end{array}$ & $\begin{array}{c}2.25 \\
(1.34)\end{array}$ & $\begin{array}{c}10.1 \\
(25.5)\end{array}$ & $\begin{array}{c}8.82 \\
(16.7)\end{array}$ \\
\hline 3 & $\begin{array}{c}82.4 \\
(54.2)\end{array}$ & $\begin{array}{c}0.647 \\
(0.755)\end{array}$ & $\begin{array}{c}0.325 \\
(0.201)\end{array}$ & $\begin{array}{l}10.8 \\
(28.3)\end{array}$ & $\begin{array}{c}8.42 \\
(16.6)\end{array}$ \\
\hline 5 & $\begin{array}{c}83.3 \\
(53.1)\end{array}$ & $\begin{array}{c}0.924 \\
(1.05)\end{array}$ & $\begin{array}{c}0.564 \\
(0.339)\end{array}$ & $\begin{array}{c}10.6 \\
(27.0)\end{array}$ & $\begin{array}{c}9.70 \\
(18.5)\end{array}$ \\
\hline 10 & $\begin{array}{c}83.7 \\
(52.4)\end{array}$ & $\begin{array}{c}0.684 \\
(0.760)\end{array}$ & $\begin{array}{c}0.632 \\
(0.372)\end{array}$ & $\begin{array}{c}10.5 \\
(26.3)\end{array}$ & $\begin{array}{c}10.7 \\
(20.1)\end{array}$ \\
\hline 15 & $\begin{array}{c}83.0 \\
(55.5)\end{array}$ & $\begin{array}{l}1.37 \\
(1.64)\end{array}$ & $\begin{array}{c}0.829 \\
(0.528)\end{array}$ & $\begin{array}{c}10.5 \\
(27.9)\end{array}$ & $\begin{array}{c}7.38 \\
(14.4)\end{array}$ \\
\hline
\end{tabular}

In this analysis of EPMA, the surface of the sample was coated by Pt sputter for the purpose of electric conductivity. However, the Pt was not considered into the qualitative analysis. Thus, the sum of each element in mass $\%$ is not equal to $100 \%$.

\begin{tabular}{|c|c|c|c|c|}
\hline \multicolumn{6}{|c|}{ Solidification rate $\mathrm{V} / \mathrm{mm} \cdot \mathrm{min}^{-1}$} \\
\hline 1 & 3 & 5 & 10 & 15 \\
\hline & & & & \\
& & & & $5 \overline{500 \mu \mathrm{m}}$ \\
\hline
\end{tabular}

Fig. 16-Micrographs Obtained by $\mathrm{OM}$ at Various Solidification Rates $(V=1,3,5,10,15 \mathrm{~mm} / \mathrm{min})$ at $z=60 \mathrm{~mm}$. Dark gray parts are precipitates.

through the melt pool length $l$. Figure 23(a) shows the relationship between the solidification rate and carbon amount derived from melted $\mathrm{TiC}$, and the carbon amount is larger when the solidification rate is smaller. Considering a total carbon amount of 0.270 mass pct from 2.0 vol pct added $\mathrm{TiC}$ particles, most of the $\mathrm{TiC}$ particles were melted in molten Ti6Al4V at any solidification rate. Figure 23(b) shows the relationship between the melting time and the carbon amount derived from the melting of TiC. As the solidification rate decreases, the melting time is longer, and the carbon amount is also larger. This is because, as the melting time increased, the time that $\mathrm{TiC}$ particles were held in the molten Ti6Al4V was also longer at a lower solidification rate, and it became easier to diffuse the carbon of the $\mathrm{TiC}$ particles into the molten Ti6Al4V, partially melting the TiC. Previous research demonstrated that $\mathrm{TiC}$ particles partially melted in molten Ti6Al4V, and 
the residual $\mathrm{TiC}$ particles generated fine and equiaxed grains from the heterogeneous nuclei during the directional solidification of Ti6Al4V. ${ }^{[14]}$ From the above, it can be concluded that at a higher solidification rate, the amount of melted $\mathrm{TiC}$ particles is smaller, and the amount of residual potent heterogeneous nuclei $\mathrm{TiC}$ particles is larger.

\section{Constitutional Undercooling $\Delta T_{\mathrm{C}}$ and Nucleated Grains from Each Heterogeneous Nuclei Radius}

From the solute profiles of aluminum and vanadium, the liquidus temperature in front of the solidification front was obtained using linearized binary phase diagrams of the Ti4V-Al and Ti6Al-V systems calculated by Thermo-Calc. Calculating the constitutional undercooling $\Delta T_{\mathrm{c}}$ from Figure 24(a), the maximum constitutional undercooling $\Delta T_{\mathrm{c}, \operatorname{Max}}$ is $0.439 \mathrm{~K}$ at $V=1 \mathrm{~mm} / \mathrm{min}$, $0.493 \mathrm{~K}$ at $V=3 \mathrm{~mm} / \mathrm{min}, 0.626 \mathrm{~K}$ at $V=5 \mathrm{~mm} / \mathrm{min}$, $0.762 \mathrm{~K}$ at $V=10 \mathrm{~mm} / \mathrm{min}$, and $1.08 \mathrm{~K}$ at $V=15 \mathrm{~mm} /$

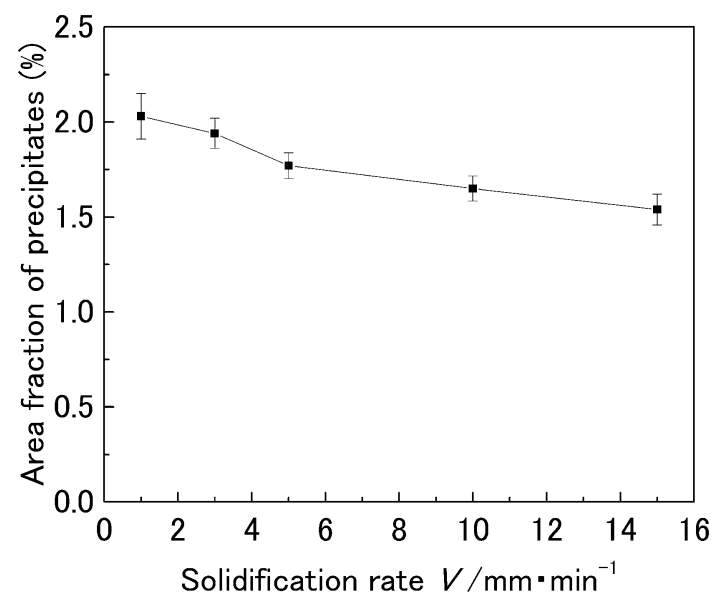

Fig. 17-Relationship between area fraction of the precipitates and solidification rate obtained from the floating zone melting experiments. Error bars show the area fraction variations of the precipitates, and they were the average value of three points $(z=20,40$, and $60 \mathrm{~mm})$.

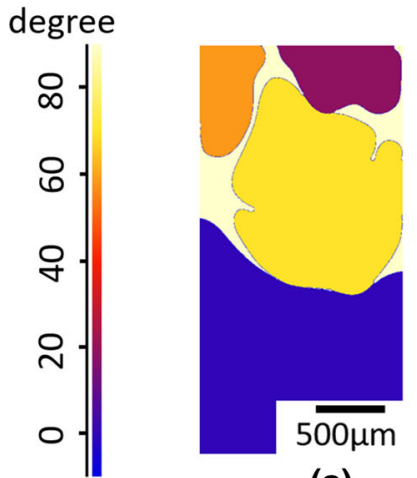

(a)

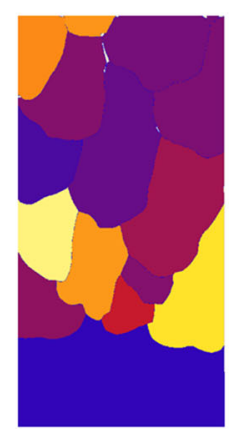

(b)

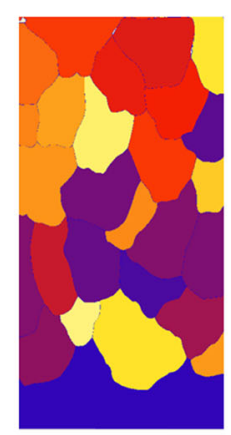

(c)

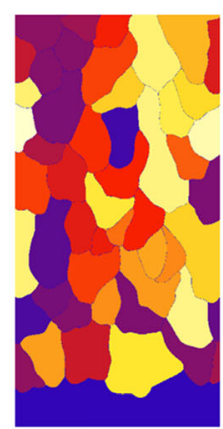

(d)

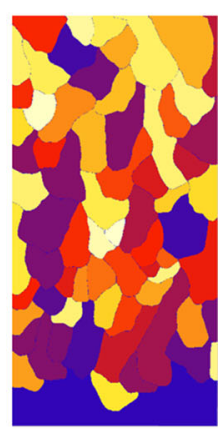

(e)

Fig. 18-Simulated Ti6Al4V microstructure for each $G$ and $V$ condition of the floating zone experiment. The color bar shows the crystal orientation of the grains. (a) $V=1 \mathrm{~mm} / \mathrm{min},(b) V=3 \mathrm{~mm} / \mathrm{min},(c) V=5 \mathrm{~mm} / \mathrm{min},(d) V=10 \mathrm{~mm} / \mathrm{min}$, and $(e) V=15 \mathrm{~mm} / \mathrm{min}$. 


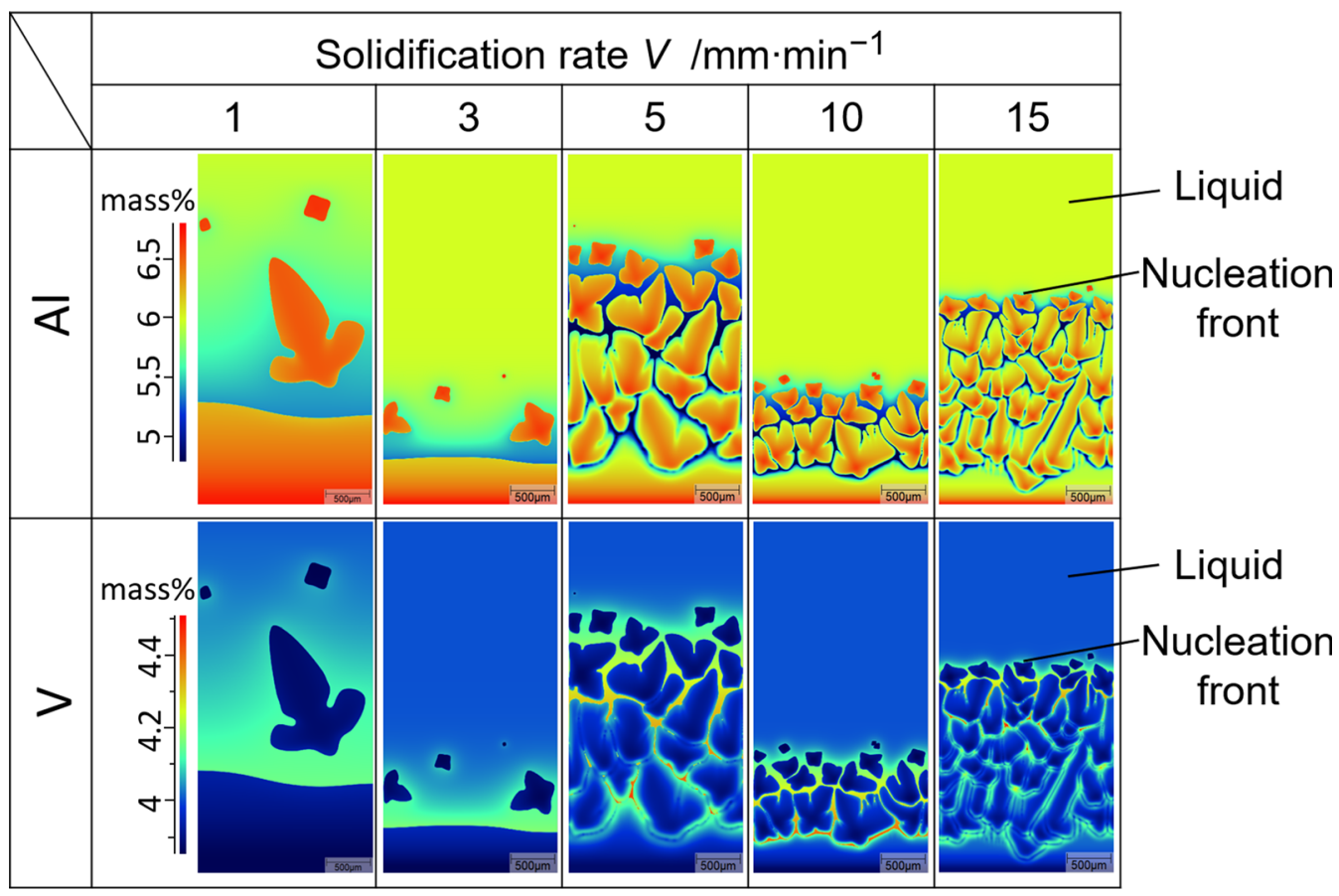

Fig. 19-Predicted segregation of aluminum (Al) and vanadium (V) during solidification obtained by phase field simulation.
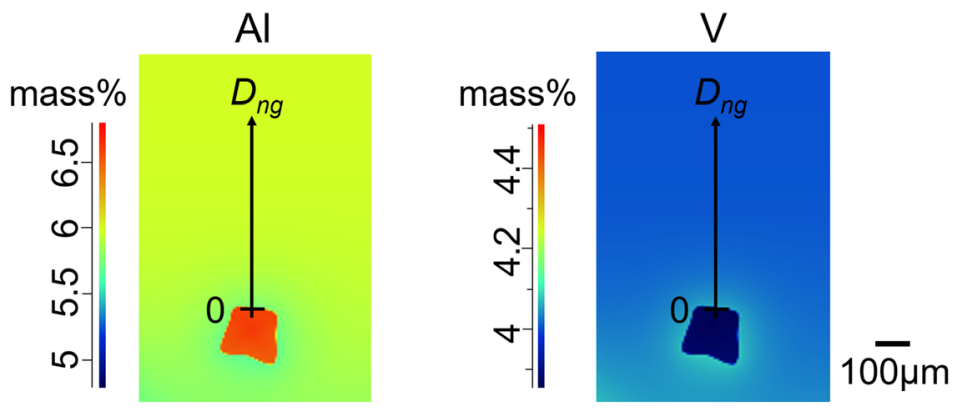

(a)

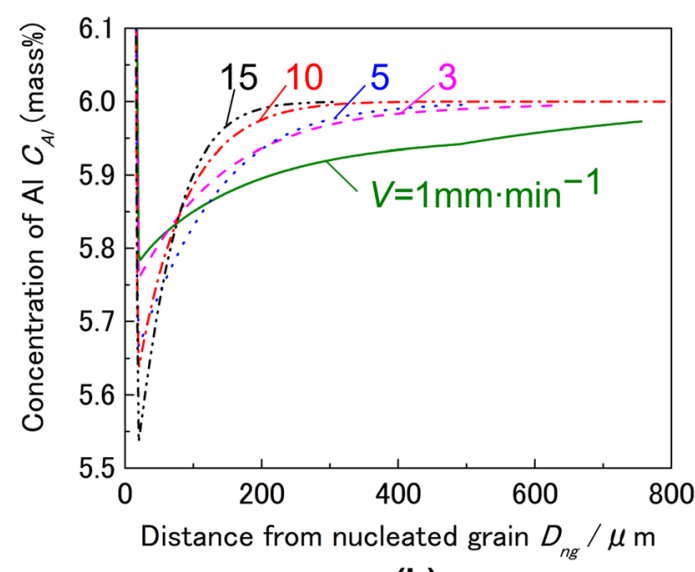

(b)

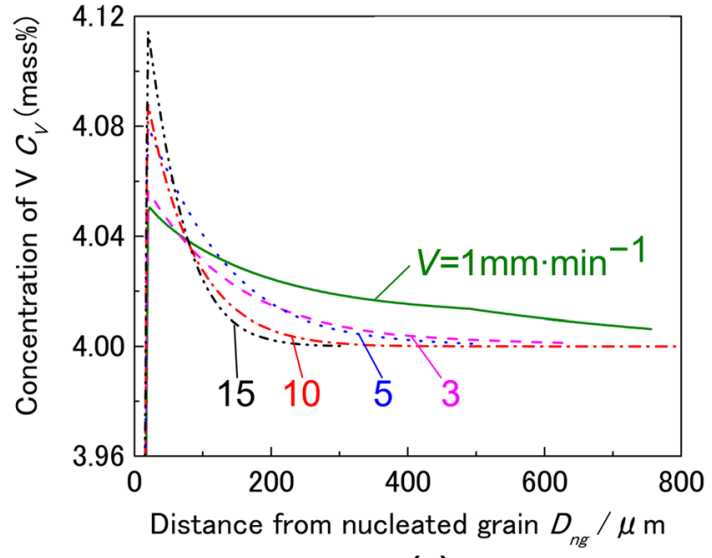

(c)

Fig. 20-(a) Predicted segregation of aluminum and vanadium at the nucleation front (interface between the nucleated grain and liquid is defined as the distance from the nucleated grain $\left.d_{\mathrm{ng}}=0\right)$, and solute profiles of $(b)$ aluminum and $(c)$ vanadium extracted from the nucleation front obtained by phase field simulation. 


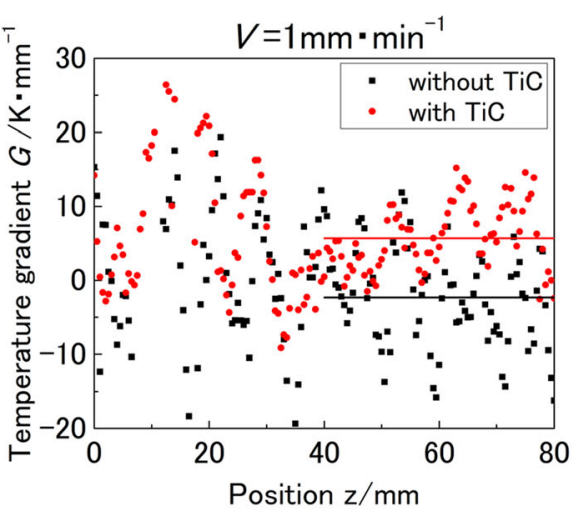

Average: without $\mathrm{TiC}=-2.33 \mathrm{~K} \cdot \mathrm{mm}^{-1}$ with $\mathrm{TiC}=5.69 \mathrm{~K} \cdot \mathrm{mm}^{-1}$

(a)

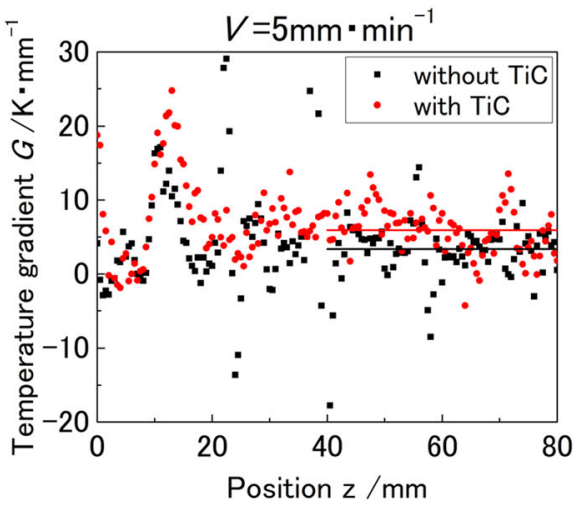

Average: without $\mathrm{TiC}=3.36 \mathrm{~K} \cdot \mathrm{mm}^{-1}$ with $\mathrm{TiC} \quad=5.91 \mathrm{~K} \cdot \mathrm{mm}^{-1}$ (c)

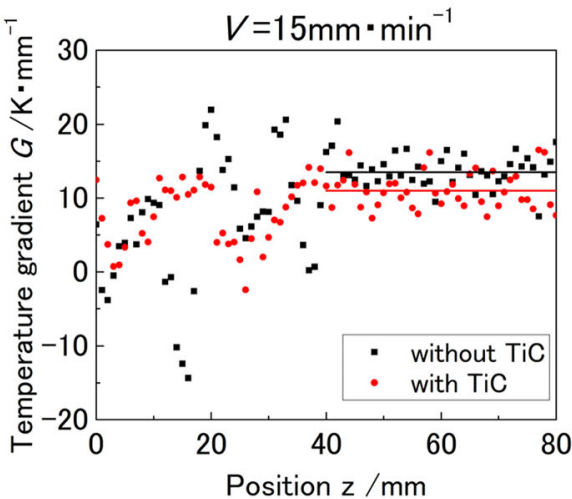

Average: without $\mathrm{TiC}=13.5 \mathrm{~K} \cdot \mathrm{mm}^{-1}$ with $\mathrm{TiC}=11.0 \mathrm{~K} \cdot \mathrm{mm}^{-1}$

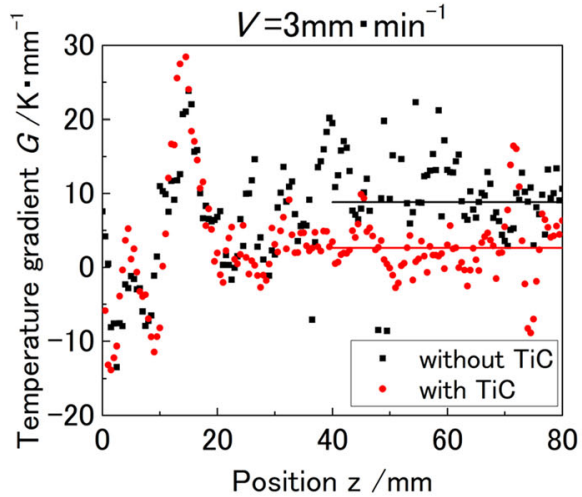

Average: without $\mathrm{TiC}=8.82 \mathrm{~K} \cdot \mathrm{mm}^{-1}$ with $\mathrm{TiC} \quad=2.63 \mathrm{~K} \cdot \mathrm{mm}^{-1}$

(b)

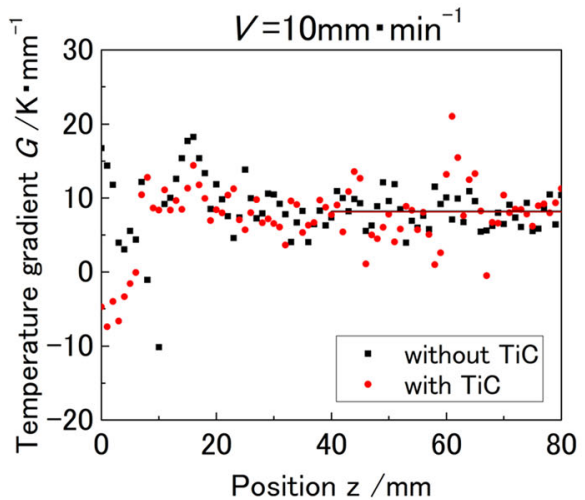

Average: without $\mathrm{TiC}=8.16 \mathrm{~K} \cdot \mathrm{mm}^{-1}$ with $\mathrm{TiC}=8.13 \mathrm{~K} \cdot \mathrm{mm}^{-1}$

(d)

(e)

Fig. 21-Temperature gradient $G$ at various solidification rates $(V=1,3,5,10$, and $15 \mathrm{~mm} / \mathrm{min})$ between the positions of $z=0$ and $80 \mathrm{~mm}$. The black and red lines in the figure show the average temperature gradient $G$ between $z=40$ and $80 \mathrm{~mm}$ without and with TiC respectively. (a) $V=1 \mathrm{~mm} / \mathrm{min},($ b) $V=3 \mathrm{~mm} / \mathrm{min},(c) V=5 \mathrm{~mm} / \mathrm{min}$, (d) $V=10 \mathrm{~mm} / \mathrm{min}$, and (e) $V=15 \mathrm{~mm} / \mathrm{min}$. 


\section{Effect of Temperature Gradient $G$ and Cooling Rate $R$ by Phase Field Simulation}

In general, it is well known that not only the solidification rate $V$ but also the temperature gradient $G$ and cooling rate $R$ also affect the solidification microstructure. ${ }^{[23,24]}$ Figure 25(a) shows the simulated microstructure at various temperature gradients $G(G=$ $12,24,30$, and $36 \mathrm{~K} / \mathrm{mm})$ at the same cooling rate $R(3$

Table VI. Atomic Fraction of Elements in Precipitate Except for Oxygen Obtained With EPMA (mol\%)

\begin{tabular}{lcccc}
\hline Solidification Rate $V / \mathrm{mm} \cdot \mathrm{min}^{-1}$ & $\mathrm{Ti}$ & $\mathrm{Al}$ & $\mathrm{V}$ & $\mathrm{C}$ \\
\hline 1 & 65.2 & 2.56 & 1.61 & 30.6 \\
3 & 64.9 & 0.904 & 0.241 & 33.9 \\
5 & 65.2 & 1.28 & 0.415 & 33.1 \\
10 & 65.6 & 0.951 & 0.466 & 33.0 \\
15 & 65.2 & 1.36 & 0.402 & 33.0 \\
\hline
\end{tabular}

$\mathrm{K} / \mathrm{s}$ ), and the number of nucleated grains became smaller as the temperature gradient increased. Figure 25(b) shows the constitutional undercooling $\Delta T_{\mathrm{C}}$ at the nucleation front. Constitutional undercooling became smaller as the temperature gradient increased; in particular, at $G=36 \mathrm{~K} / \mathrm{mm}$, constitutional undercooling did not appear. Figure 25(c) shows the nucleated grains and heterogeneous nuclei radius. As the temperature gradient increased, the number of nucleated grains became smaller, and the smaller radius of heterogeneous nuclei became more difficult to nucleate. In addition, nucleation did not occur when $G=36 \mathrm{~K} /$ $\mathrm{mm}$, at which the constitutional undercooling $\Delta T_{\mathrm{C}}$ did not appear. From these results, it is considered that as the temperature gradient increases under the same cooling rate, constitutional undercooling becomes smaller. Thus, the smaller radius of the heterogeneous nuclei became more difficult to nucleate and the nucleation probability became smaller.

The effect of a higher cooling rate, $R$, was also investigated. Here, the cooling rate $R$ was set to be 3,10 ,

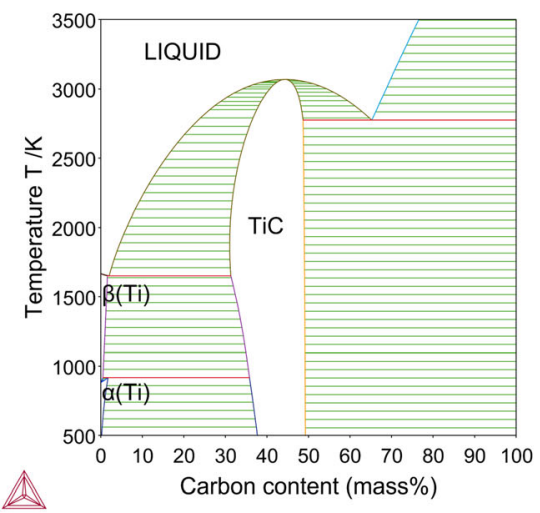

(a)

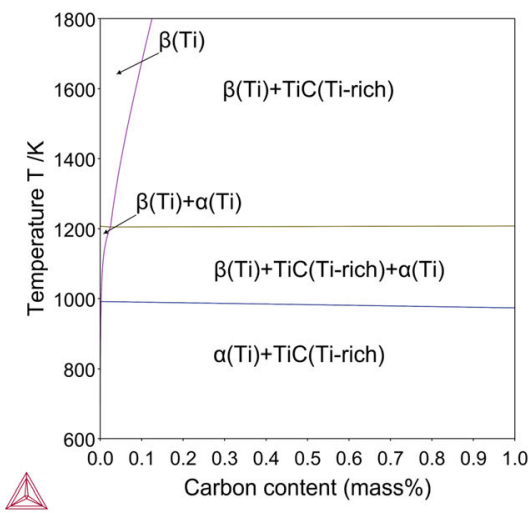

(b)

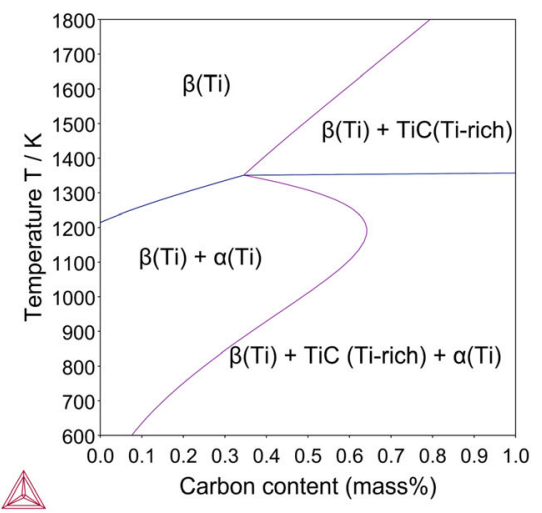

(c)

Fig. 22-Predicted phase diagrams of $(a)$ the binary TiC system (SSOL7 was used as the Ti-alloys database), (b) pseudo-binary Ti6Al4V-C system (SSOL7 was used as the Ti-alloys database), and (c) pseudo-binary Ti6Al4V-C system (TTTI3 was used as the Ti-alloys database).

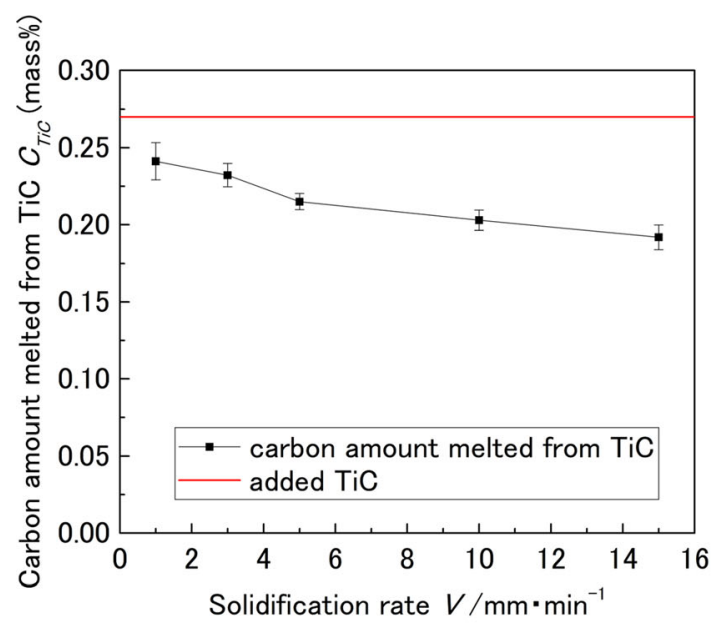

(a)

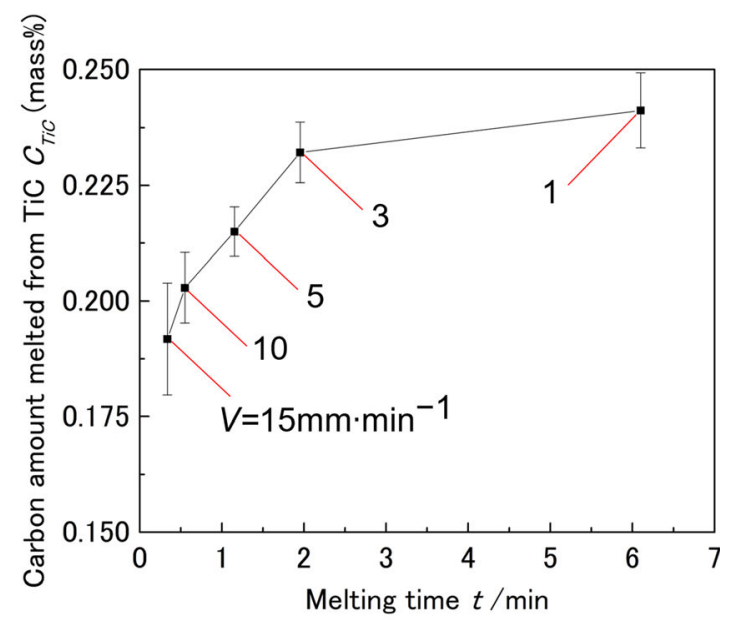

(b)

Fig. 23-Effects of solidification rate on the carbon amount melted from TiC. (a) Relationship between solidification rate and carbon amount melted from $\mathrm{TiC}$, and $(b)$ relationship between melting time and carbon amount derived melted from TiC. 


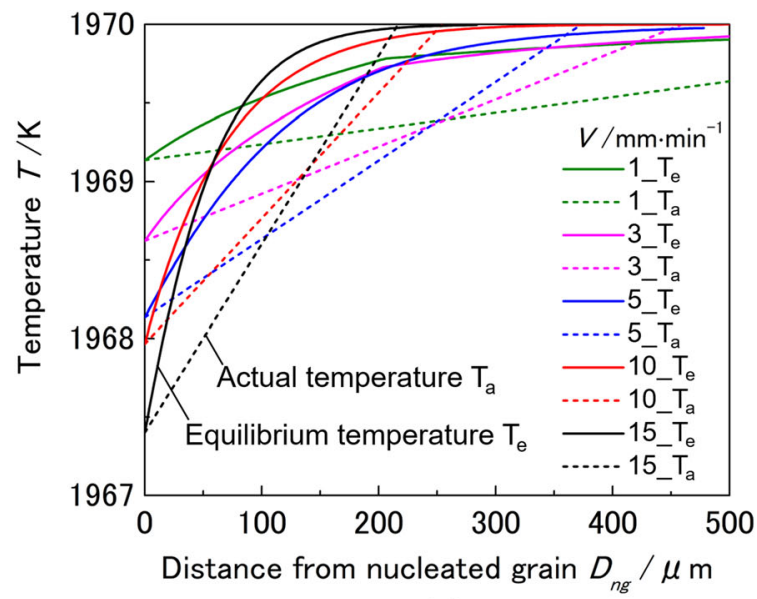

(a)

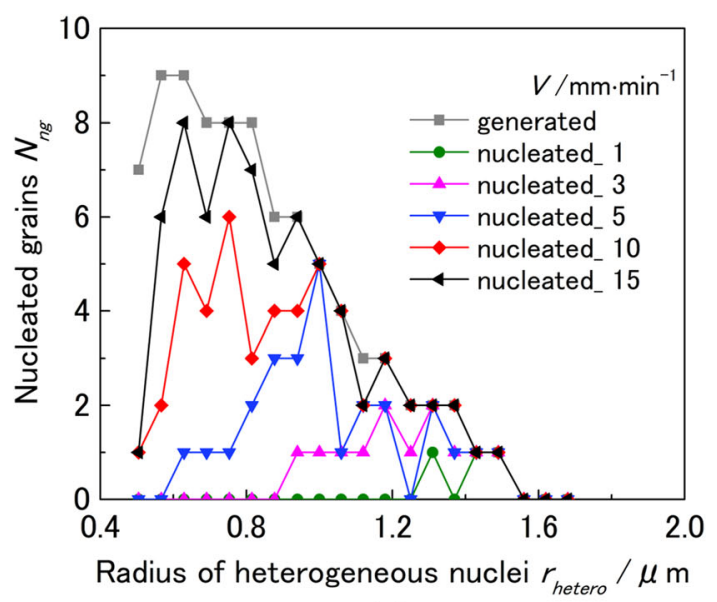

(b)

Fig. 24 -Effect of solidification rate on $G, V$ conditions of the floating zone experiment obtained by phase field simulation. (a) Constitutional undercooling at nucleation front; the solid line shows the equilibrium temperature $T_{\mathrm{e}}$, and the dotted line shows the actual temperature $T_{\mathrm{a}}$. $(b)$ The number of nucleated grains for each heterogeneous nucleus radius.
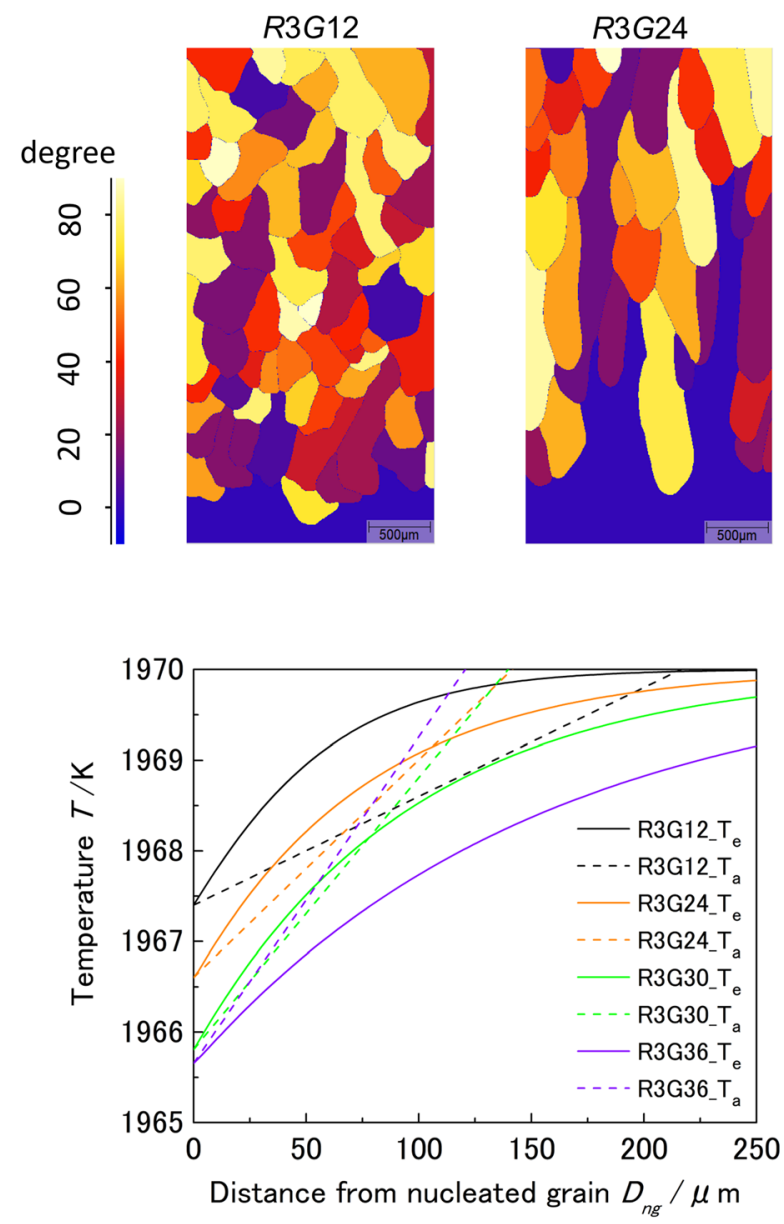

(b)

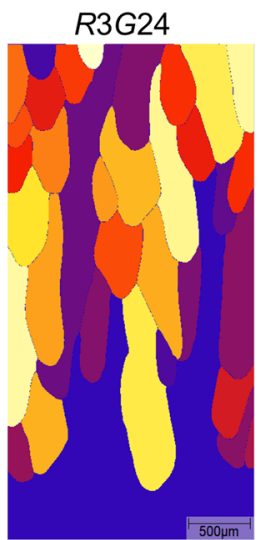

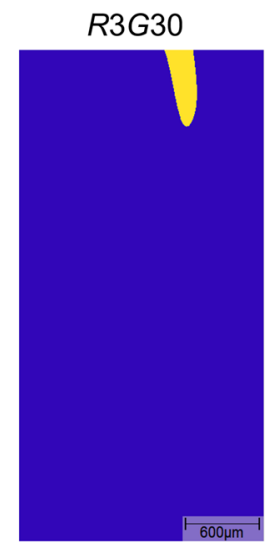

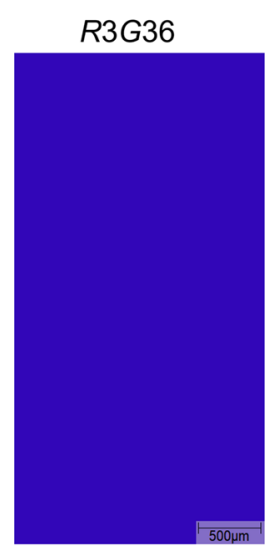

(a)

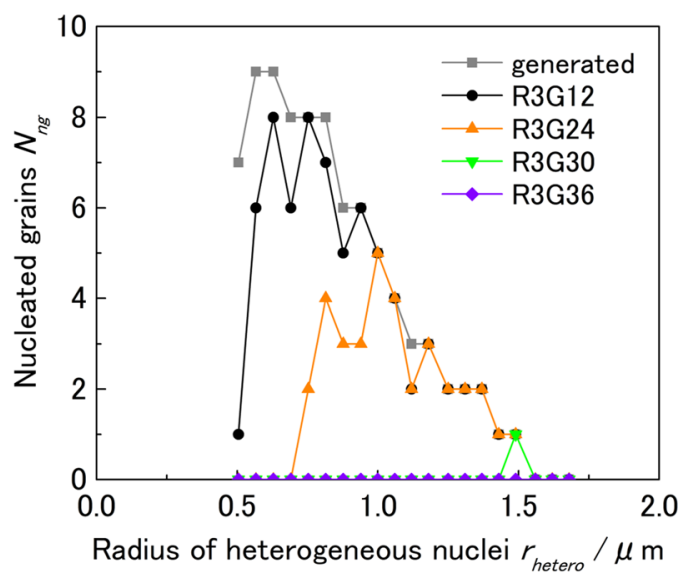

(c)

Fig. 25-Effect of temperature gradient $G$ at the same cooling rate $R$ obtained by phase field simulation. (a) Simulated microstructure, where $R 3 G 12$ refers to a cooling rate of $R=3 \mathrm{~K} / \mathrm{s}$ and temperature gradient of $G=12 \mathrm{~K} / \mathrm{mm}$ (the same pattern is used for the others); (b) constitutional undercooling $\Delta T_{\mathrm{c}}$ at the nucleation front, where the solid line shows the equilibrium temperature $T_{\mathrm{e}}$ and the dotted line shows the actual temperature $T_{\mathrm{a}} ;(c)$ nucleated grains and heterogeneous nuclei radius. 
$50,100,500$, and $1000 \mathrm{~K} / \mathrm{s}$, and the temperature gradient $G$ was constant $(10 \mathrm{~K} / \mathrm{mm})$. Figure 26 (a) shows the simulated microstructure, and the number of nucleated grains is 70 when $R=3 \mathrm{~K} / \mathrm{s}, 84$ when $R=50 \mathrm{~K} / \mathrm{s}$, and 84 when $R=1000 \mathrm{~K} / \mathrm{s}$. Figure 26(b) shows the constitutional undercooling at the nucleation front, and the degree of constitutional undercooling increased as the cooling rate increased up to $50 \mathrm{~K} / \mathrm{s}$; however, the degree of constitutional undercooling was smaller at $R$ $=1000 \mathrm{~K} / \mathrm{s}$ than at $50 \mathrm{~K} / \mathrm{s}$. In addition, as the cooling rate increased, the solute diffusion length decreased and the concentration gradient in the liquid ahead of the solidification front increased. It is expected that the solidification tip velocity is much higher than the velocity of solute diffusion. Figure 26(c) shows the relationship between the cooling rate $R$ and the maximum degree of constitutional undercooling $\Delta T_{\mathrm{c}, \mathrm{Max}}$. In the region of low cooling rate $(\sim 50 \mathrm{~K} / \mathrm{s}), \Delta T_{\mathrm{c}, \text { Max }}$ increased as the cooling rate increased. However, in the region of higher cooling rate, $\Delta T_{\mathrm{c}, \mathrm{Max}}$ has a peak value, after which $\Delta T_{\mathrm{c}}$ decreases as the cooling rate increases. As shown in Figure 26(a), comparing the microstructures of $R=50 \mathrm{~K} / \mathrm{s}$ and $R=1000 \mathrm{~K} / \mathrm{s}$, the grain number of $R=1000 \mathrm{~K} / \mathrm{s}$ and $R=50 \mathrm{~K} / \mathrm{s}$ is the same even though the constitutional undercooling $\Delta T_{\mathrm{c}, \mathrm{Max}}$ of $R=1000 \mathrm{~K} / \mathrm{s}$ is lower than that of $R=50 \mathrm{~K} / \mathrm{s}$. Thus, it is suggested that constitutional undercooling $\Delta T_{\mathrm{c}}$ has less contribution at higher cooling rates. In general, nucleation occurs more frequently as the cooling rate increases. However, in the simulation, the number of distributed heterogeneous nuclei in the simulation domain was set to 84 from the input seed density model, and the maximum number of nucleation events was limited. Therefore, a further increase in nucleation did not occur when the cooling rate $R$ was larger than approximately $50 \mathrm{~K} / \mathrm{s}$.

Thus, at low cooling rates, the constitutional undercooling $\Delta T_{\mathrm{c}}$ mainly promotes nucleation. On the other hand, for high cooling rates, constitutional undercooling contributes less to grain refinement, and thermal undercooling $\Delta T_{\mathrm{t}}$ generated by the cooling rate promotes nucleation. Because the cooling rate of the floating zone experiment was $R=\sim 3 \mathrm{~K} / \mathrm{s}$, it is considered that constitutional undercooling $\Delta T_{\mathrm{c}}$ activated the heterogeneous $\mathrm{TiC}$ nuclei and promoted nucleation.
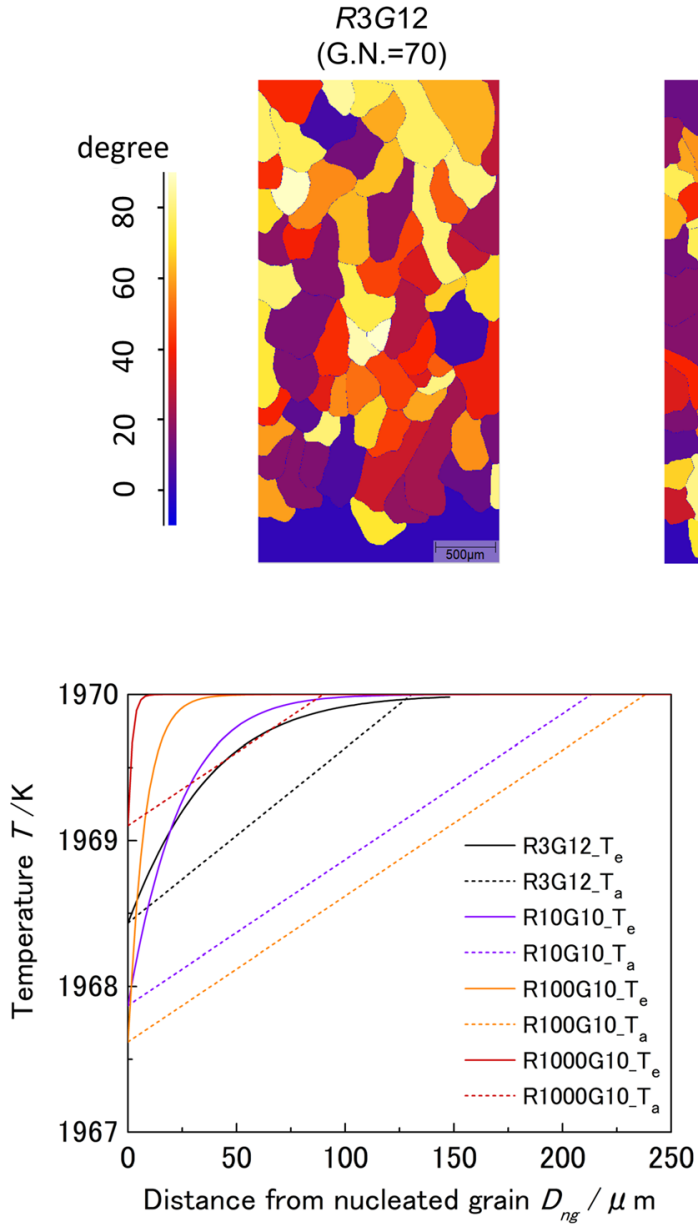

(b)

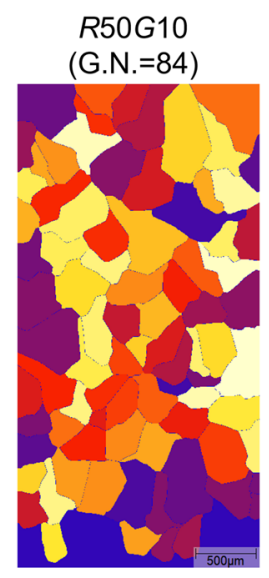

(a)

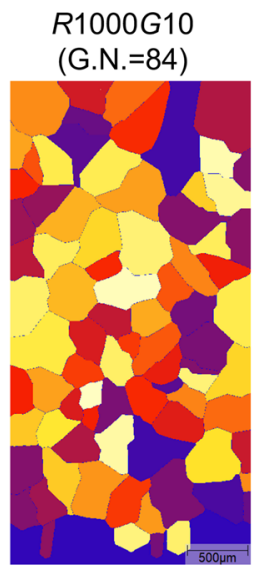

$R 1000 G 10$

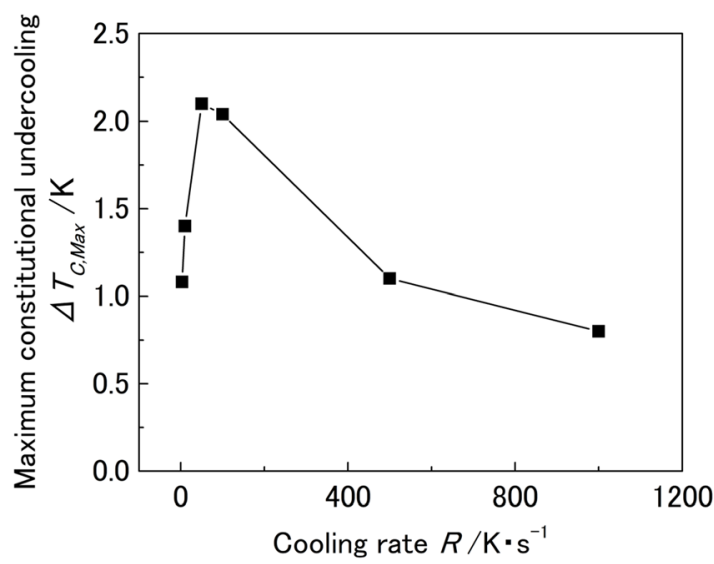

(c)

Fig. 26-Effect of cooling rate $R$ under the same temperature gradient $G$ obtained by phase field simulation. (a) Simulated microstructure, where $R 50 G 10$ refers to a cooling rate $R=50 \mathrm{~K} / \mathrm{s}$ and temperature gradient of $G=10 \mathrm{~K} / \mathrm{mm}$ (the same pattern is used for the others), and $\mathrm{G}$.N. refers to the number of nucleated grains in the simulation domain; $(b)$ constitutional undercooling at the nucleation front, where the solid line shows the equilibrium temperature $T_{\mathrm{e}}$ and the dotted line shows the actual temperature $T_{\mathrm{a}} ;(c)$ relationship between $\Delta T_{\mathrm{c}, \mathrm{Max}}$ and cooling rate $R$. 


\section{E. Solidification map}

Figure 27(a) shows the solidification map in the region of the floating zone experiment $(R<3 \mathrm{~K} / \mathrm{s})$. The black dotted line in the figure shows the criteria of heterogeneous nucleation from $\mathrm{TiC}$ by phase field simulation, and nucleation from $\mathrm{TiC}$ is predicted in the area above the line. On the other hand, no nucleation from $\mathrm{TiC}$ is predicted in the area below the line. As shown in the figure, the nucleation criteria and experimental results were almost in agreement except for $V=1 \mathrm{~mm} / \mathrm{min}$ in the region of the floating zone experiment. Figure 27(b) shows the map in the region where there was a higher cooling rate $R$ than in the $\mathrm{FZ}$ experiment ( $R=3$ to $1000 \mathrm{~K} / \mathrm{s}$ ). In general, the cooling rate of casting is approximately 3 to $100 \mathrm{~K} / \mathrm{s},{ }^{[25]}$ welding is approximately 100 to $700 \mathrm{~K} / \mathrm{s},{ }^{[26,27]}$ electron beam melting (EBM) is approximately 1000 to $2 \times 10^{5}$ $\mathrm{K} / \mathrm{s},{ }^{[28,29]}$ and laser powder bed fusion (LPBF) is approximately $1 \times 10^{6} \mathrm{~K} / \mathrm{s} \cdot{ }^{[30,31]}$ In the figure, the lower left, middle, and upper right areas are roughly equivalent to casting, welding, and EBM, respectively. When the map shows a much broader range, LPBF is equivalent to the upper right region. In this map, EBM region includes LPBF.

By using this solidification map, the conditions under which the heterogeneous $\mathrm{TiC}$ nuclei are activated in the Ti6Al4V alloy can be predicted. In other words, grain refinement of Ti6Al4V by heterogeneous $\mathrm{TiC}$ nuclei can be achieved by setting the conditions of temperature gradient $G$ and solidification rate $V$ in the area above the nucleation criteria. Furthermore, this solidification map can be applied to other processes, such as directional solidification, casting, and welding. Eventually, it can also be applied to EBM including LPBF and consequently, grain refinement can be achieved more effectively in the Ti6A14V-TiC system.

In particular, at $V=1 \mathrm{~mm} / \mathrm{min}$ in Figure 27(a), the simulation output shows that heterogeneous nuclei $\mathrm{TiC}$ nucleated; however, the FZ experiment results show that TiC particles did not work as heterogeneous nuclei at $V$ $=1 \mathrm{~mm} / \mathrm{min}$, suggesting no nucleation from TiC because the prior $\beta$ GB did not appear above $z=40$ $\mathrm{mm}$, and there were no significant differences above $z=$ $40 \mathrm{~mm}$ between with and without $\mathrm{TiC}$. In the floating zone experiment, the $\mathrm{TiC} 2.0 \mathrm{vol}$ pct ( $\mathrm{TiC} 0.340 \mathrm{~g}$ ) sample contained $6.4 \times 10^{12}$ particles and the number of nucleated grains was on the order of 150 . The probability of nucleation in the FZ experiment was very low. In contrast, many grains nucleated in the phase field simulation, and the probability of nucleation was very high in this simulation. There are three possible explanations for this contradiction. First, in the phase field simulation, latent heat from grains was not considered, and whether or not $\mathrm{TiC}$ particles nucleated depended on thermodynamic judgment. In actuality, the latent heat released by previously growing grains will cause an accelerated consumption of nucleation undercooling in the remaining melt, rendering the relatively smaller particles inefficient for nucleation, and then the percentage of effective particles will decrease. ${ }^{[10]}$ Second, in the phase field simulation, to model heterogeneous nucleation from TiC particles, a free growth model was used. The value for the critical undercooling $\Delta T_{\mathrm{n}}$ from $\mathrm{TiC}$ was calculated from the particle size according to the hemispherical cap model. In this model, complete wetting between the heterogeneous nuclei $\mathrm{TiC}$ and $\beta$ grains (contact angle $\theta=0^{\circ}$ ) was assumed, and it was very easy to nucleate. However, in actual situations, the heterogeneous nuclei $\mathrm{TiC}$ and $\beta$ grains are not completely wet (contact angle $0<\theta<90^{\circ}$ ) and are harder to nucleate than when complete wetting is present. Therefore, the nucleation probability is much higher in the simulation than in the FZ experiment. At last, TiC particles were melted during directional solidification of the FZ experiment, and as the solidification rate increased, the amount of melted $\mathrm{TiC}$ was smaller and the amount of residual $\mathrm{TiC}$ particles was larger under the experimental conditions. However, in the phase field simulation, the melting of $\mathrm{TiC}$ particles was not taken into account, and the amount of heterogeneous nuclei was at the same level regardless of the solidification rates. By considering these three assumptions, a more

\section{$G, V$ region of $F Z$ exp.}

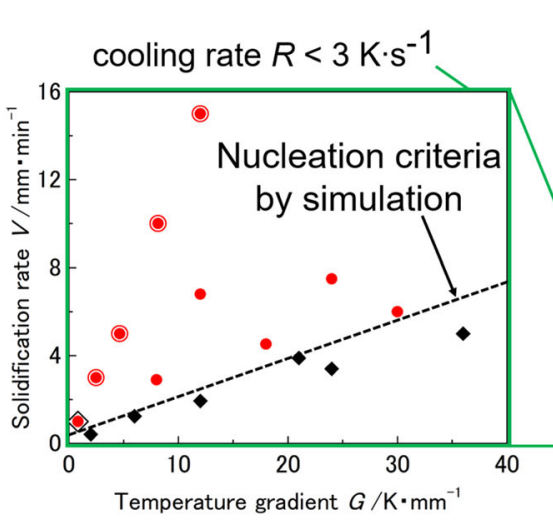

(a)

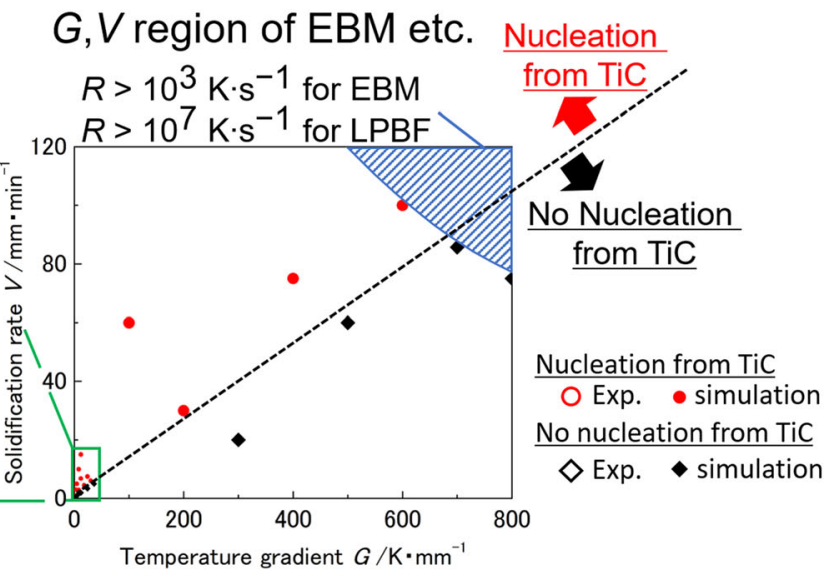

(b)

Fig. 27-Solidification map. (a) $G, V$ region of the floating zone experiment $(R<3 \mathrm{~K} / \mathrm{s})$; $(b)$ in the region where the cooling $R$ rate was higher than in the FZ experiment $(R<1000 \mathrm{~K} / \mathrm{s})$. 
precise simulation could be conducted and the criteria of heterogeneous nucleation from $\mathrm{TiC}$ by phase field simulation could be included, which could reproduce the experimental results at $V=1 \mathrm{~mm} / \mathrm{min}$.

\section{CONCLUSION}

In this study, the effects of solidification conditions on the grain refinement capacity of $\mathrm{TiC}$ in directionally solidified Ti6Al4V alloy were investigated. In addition, the temperature gradient $G$ and solidification rate $V$ conditions under which $\mathrm{TiC}$ is activated and grain refinement can be achieved in the Ti6Al4V-TiC system were investigated. The following results were obtained from experimental and numerical approaches.

In the $G$ and $V$ regions of the floating zone melting experiment $(R<3 \mathrm{~K} / \mathrm{s})$, a relatively small size of prior $\beta$ grains appeared in the directionally solidified Ti6Al4V alloy by TiC addition at $V>1 \mathrm{~mm} / \mathrm{min}$. In addition, the increase in grain number with the addition of $\mathrm{TiC}$ increased as the solidification rate increased. This is because, as the solidification rate increases, the amount of melted $\mathrm{TiC}$ decreases (the fraction of $\mathrm{Ti}_{2} \mathrm{C}$ precipitates is smaller) and the amount of residual potent heterogeneous nuclei TiC increases. Second, based on the phase field simulation, increasing the constitutional undercooling $\Delta T_{\mathrm{c}}$ leads to the activation of a smaller radius of heterogeneous nuclei and a higher nucleation probability from each radius.

In the region where the cooling rate $R$ is higher than in the floating zone melting experiment $(R=3$ to 1000 $\mathrm{K} / \mathrm{s}$ ), the maximum degree of constitutional undercooling $\Delta T_{\mathrm{c}, \text { Max }}$ has a peak value when the temperature gradient $G$ is constant. This suggests that constitutional undercooling $\Delta T_{\mathrm{c}}$ has less contribution at higher cooling rates, such as those that occur in EBM and LPBF, which is typical in additive manufacturing.

\section{ACKNOWLEDGMENTS}

This research was supported by Japan Science and Technology (JST), under the Industrial-Academia Collaborative R\&D Program "Heterogeneous Structure Control: Towards Innovative Development of Metallic Structural Materials." Grant Number JPMJSK1614.

\section{OPEN ACCESS}

This article is licensed under a Creative Commons Attribution 4.0 International License, which permits use, sharing, adaptation, distribution and reproduction in any medium or format, as long as you give appropriate credit to the original author(s) and the source, provide a link to the Creative Commons licence, and indicate if changes were made. The images or other third party material in this article are included in the article's Creative Commons licence, unless indicated otherwise in a credit line to the material. If material is not included in the article's Creative Commons licence and your intended use is not permitted by statutory regulation or exceeds the permitted use, you will need to obtain permission directly from the copyright holder. To view a copy of this licence, visit http://creat ivecommons.org/licenses/by/4.0/.

\section{REFERENCES}

1. M. Rinner, J. Gerlach, and W. Ensinger: Surf. Coat. Technol., 2000, vol. 132, pp. 111-16.

2. I. Gurrappa: Mater. Charact., 2003, vol. 51, pp. 131-39.

3. N.W. Khun, A.W.Y. Tan, W. Sun, and E. Liu: J. Therm. Spray Technol., 2017, vol. 26, pp. 1393-1407.

4. A.A. Antonysamy, J. Meyer, and P.B. Prangnell: Mater. Charact., 2013, vol. 84, pp. 153-68.

5. A. Cibula: J. Inst. Metals, 1949-50, vol. 76, pp. 321-60.

6. I.G. Davies, J.M. Dennis, and A. Hellawell: Metall. Trans., 1970, vol. 1, pp. 275-80.

7. Y. Watanabe, R. Yamazaki, K. Yamanaka, and H. Sato: $J$. Mater. Proc. Tech., 2018, vol. 255, pp. 400-10.

8. P.S. Mohanty and J.E. Gruzleski: Acta Metall. Mater., 1995, vol. 43, pp. 2001-12.

9. B.S. Murty, S.A. Kori, and M. Chakraborty: Int Mater. Rev., 2002, vol. 47, pp. 3-29.

10. L. Zhou, F. Gao, G.S. Peng, and N. Alba-Baena: J. Alloys Compd., 2016, vol. 689, pp. 401-407.

11. S. Tedman-Jones, S.D. McDonald, M.J. Bermingham, D.H. StJhon, and M.S. Dargusch: J. Alloys Compd., 2019, vol. 794, pp. 268-84.

12. M.J. Bermingham, D.H. StJohn, J. Krynen, S. Tedman-Jones, and M.S. Dargusch: Acta Mater., 2019, vol. 168, pp. 261-74.

13. Y. Watanabe, M. Sato, T. Chiba, N. Sato, and S. Nakano: Metall. Mater. Trans. A, 2020, vol. 51, pp. 1345-52.

14. S. Yamamoto, N. Date, Y. Mori, S. Suzuki, Y. Watanabe, S. Nakano, and N. Sato: Metall. Mater. Trans. A, 2019, vol. 50, pp. 3174-85.

15. B. Bottger, J. Eiken, and I. Steinbach: Acta Mater., 2006, vol. 54, pp. 2697-2704.

16. S. Nomoto, S. Minamoto, and K. Nakajima: ISIJ Inter., 2009, vol. 49, pp. 1019-1023.

17. B. Vandenbroucke and J.P. Kruth: Rapid Prototyp. J., 2007, vol. 13, pp. 196-203.

18. H. Holleck: J. Vac. Sci. Technol. A, 1986, vol. 4, pp. 2661-69.

19. R. Becker: Ann. Phys., 1938, vol. 424, pp. 128-40.

20. X. Gong and K. Chou: JOM, 2015, vol. 67, pp. 1176-82.

21. A.L. Greer, A.M. Bunn, A. Tronche, P.V. Evans, and D.J. Bristow: Acta Mater., 2000, vol. 48, pp. 2823-35.

22. J.J.Z. Li, W.L. Johnson, and W.-K. Rhim: Appl. Phys. Lett., 2006, vol. 89, p. 111913.

23. J.D. Hunt: Mater. Sci. Eng., 1984, vol. 65, pp. 75-83.

24. E. Liotti, C. Arteta, A. Zisserman, A. Lui, V. Lempitsky, and P.S. Grant: Sci.Adv., 2018, vol. 4, eaar4004.

25. C.-L. Yang, Y.-B. Li, B. Dang, H.-B. Lu, and F. Liu: Trans. Nonferrous Met. Soc. China, 2015, vol. 25, pp. 3189-96.

26. G. Turichin, M. Kuznetsov, A. Pozdnyakov, S. Gook, A. Gumenyuk, and M. Rethmeier: Procedia CIRP, 2018, vol. 74, pp. $748-51$.

27. D. Das, D.K. Pratihar, and G. Gopal Roy: Int. J. Adv. Manuf. Technol., 2018, vol. 97, pp. 2241-54.

28. M.M. Kirka, K.A. Unocic, N. Raghavan, F. Medina, R.R. Dehoff, and S.S. Babu: JOM, 2016, vol. 68, pp. 1012-20.

29. X. Gong, J. Lydon, K. Cooper, and K. Chou: J. Mater. Res., 2014, vol. 29, pp. 1951-59.

30. P.A. Hooper: Additive Manufacturing, 2018, vol. 22, pp. 548-59.

31. H. Eskandari and P.E.J. Rivera-Diaz-del-Castillo: Mater. Des., 2020, vol. 195 (109024), pp. 1-11.

Publisher's Note Springer Nature remains neutral with regard to jurisdictional claims in published maps and institutional affiliations. 